\title{
SOSORT consensus paper: school screening for scoliosis. Where
} are we today?

\author{
Theodoros B Grivas*1, Marian H Wade², Stefano Negrini' ${ }^{3}$, Joseph P O'Brien", \\ Toru Maruyama ${ }^{5}$, Martha C Hawes ${ }^{6}$, Manuel Rigo ${ }^{7}$, Hans Rudolf Weiss ${ }^{8}$, \\ Tomasz Kotwicki ${ }^{9}$, Elias S Vasiliadis ${ }^{1}$, Lior Neuhaus Sulam ${ }^{10}$ and \\ Tamar Neuhous ${ }^{11}$
}

\begin{abstract}
Address: ${ }^{1}$ Orthopaedic Department, "Thriasio" General Hospital, G. Gennimata Av. 19600, Magoula, Attica, Greece, ${ }^{2}$ PT Practice, New York, USA, ${ }^{3}$ ISICO (Italian Scientific Spine Institute), Milan, Italy, ${ }^{4}$ President \& CEO, National Scoliosis Foundation (NSF), Boston, USA, ${ }^{5}$ Department of Orthopaedic Surgery, Saitama MedicalCenter, Saitama Medical University, 1981 Kamodatsujido, Kawagoe, Saitama 350-8550, Japan, ${ }^{6}$ University of Arizona, Tucson AZ 85721, USA, ${ }^{7}$ Instituto Èlena Salvá, Barcelona, Spain, ${ }^{8}$ Asklepios Katharina Schroth Spinal Deformities Rehabilitation Centre, Bad Sobernheim, Germany, ${ }^{9}$ University of Medical Sciences, Poznan, Poland, ${ }^{10}$ Bpt physiotherapist specialist in treatment of spinal deformities, Moshe Dayan st. 18 Modiin, 71700, Israel and ${ }^{11}$ pt physiotherapist specialist in treatment of spinal deformities, Moshe Dayan st. 18 Modiin, 71700, Israel

Email: Theodoros B Grivas* - grivastb@vodafone.net.gr; Marian H Wade - cmjwade@msn.com; Stefano Negrini - isico@isico.it; Joseph P O'Brien - jpobrien@scoliosis.org; Toru Maruyama - tmaruyama17@ybb.ne.jp; Martha C Hawes - mhawes@u.arizona.edu; Manuel Rigo - lolo_rigo@ hotmail.com; Hans RudolfWeiss - hr.weiss@asklepios.com; Tomasz Kotwicki - kotwicki@amp.edu.pl; Elias S Vasiliadis - eliasvasiliadis@yahoo.gr; Lior Neuhaus Sulam - liormic@yahoo.com; Tamar Neuhous - tamarneu@yahoo.com

* Corresponding author
\end{abstract}

Published: 26 November 2007

Scoliosis 2007, 2:17 doi:10.1186/1748-7/61-2-17
Received: 10 November 2007

Accepted: 26 November 2007

This article is available from: http://www.scoliosisjournal.com/content/2/l/17

(c) 2007 Grivas et al; licensee BioMed Central Ltd.

This is an Open Access article distributed under the terms of the Creative Commons Attribution License (http://creativecommons.org/licenses/by/2.0), which permits unrestricted use, distribution, and reproduction in any medium, provided the original work is properly cited.

\begin{abstract}
This report is the SOSORT Consensus Paper on School Screening for Scoliosis discussed at the $4^{\text {th }}$ International Conference on Conservative Management of Spinal Deformities, presented by SOSORT, on May 2007. The objectives were numerous, I) the inclusion of the existing information on the issue, 2) the analysis and discussion of the responses by the meeting attendees to the twenty six questions of the questionnaire, 3) the impact of screening on frequency of surgical treatment and of its discontinuation, 4) the reasons why these programs must be continued, 5) the evolving aim of School Screening for Scoliosis and 6) recommendations for improvement of the procedure.
\end{abstract}

\section{Background}

Early detection of idiopathic scoliosis has been a major and growing commitment of orthopaedists since the early 1960s. A large body of literature, reporting a great deal of clinical experience, has accrued since then [1-364].

G. Dean MacEwen, MD, played an important role in the early development of school screening by implementing programs in all schools in the state of Delaware in the 1960s [43,44,149,162,179,180,237].
The start of screening for scoliosis began in 1963 in Aitken, a town with a population of about 10.000 in central Minnesota [181].

Consequently, the state of Minnesota pioneered spinal screening in the United States by implementing in 1973 a centrally-directed, statewide but voluntary program, based on clinical examination [184]. 
In USA, as of 2003, 21 States had legislated school screening; 11 States recommended school screening without legislation and the remaining either had volunteer screenings or recommended not to conduct screening in the schools, Figure 1.

The 21 legislated States are: 2002-Virginia, 1996-Utah, 1987-Arkansas, 1985-Texas, 1984-Alabama, Indiana, 1983-Georgia, Nevada, 1982-Connecticut, Kentucky, Maryland, Pennsylvania, 1981-Maine, Rhode Island, 1980-California, Massachusetts, 1979-Washington, Florida, 1978-Delaware, New Jersey, New York.

In the USA, not all legislated screening programs are the same today. We can not take a broad-brush approach to whether or not a state has screening, but must look further at screening protocol details, including age and gender screened, screener education and support, scoliometer usage, reporting and follow-up methodologies etc, to evaluate the effectiveness of a program. Some states have ratios of one school nurse for every 700 students, while others have 2000/1 ratios and use health aides and volunteer parents to perform scoliosis screening. Unfortunately, in the USA there is a lack of national standards and adequate reports for scoliosis screening mechanisms, making collection of evidence-based outcomes necessary to either enhance this process or eliminate it, extremely difficult. Perhaps a study should be first done to compare the legislative states and document the intra and inter state varia- bility of screening programs and outcome results [332,333].

Japan is the nation with a federally mandated screening program, mostly accomplished with surface topography using the moiré technique and low-dose roentgenographic techniques [275].

In Japan, school-screening program for scoliosis is mandatory by law. But actual program depends on local educational committees, as they take charge of their ownprogram. The local educational committee is set up at each city and ward. Some committees use moiré topography, while others don't. Therefore, the rate of the committees using moiré topography in Japan is unclear. With respect to the Tokyo area, the committees which use moiré surface topography are less than half [334].

The British Orthopaedic Association and the British Scoliosis Society conclude that it should not be a national policy to routinely screen children for scoliosis throughout the United Kingdom [50].

The fact that school screening programs for scoliosis remain the subject of considerable controversy is a not a new issue $[58,79,80,114,154,181,182,203,207,286,296$, 299,304,323,326,329,330].

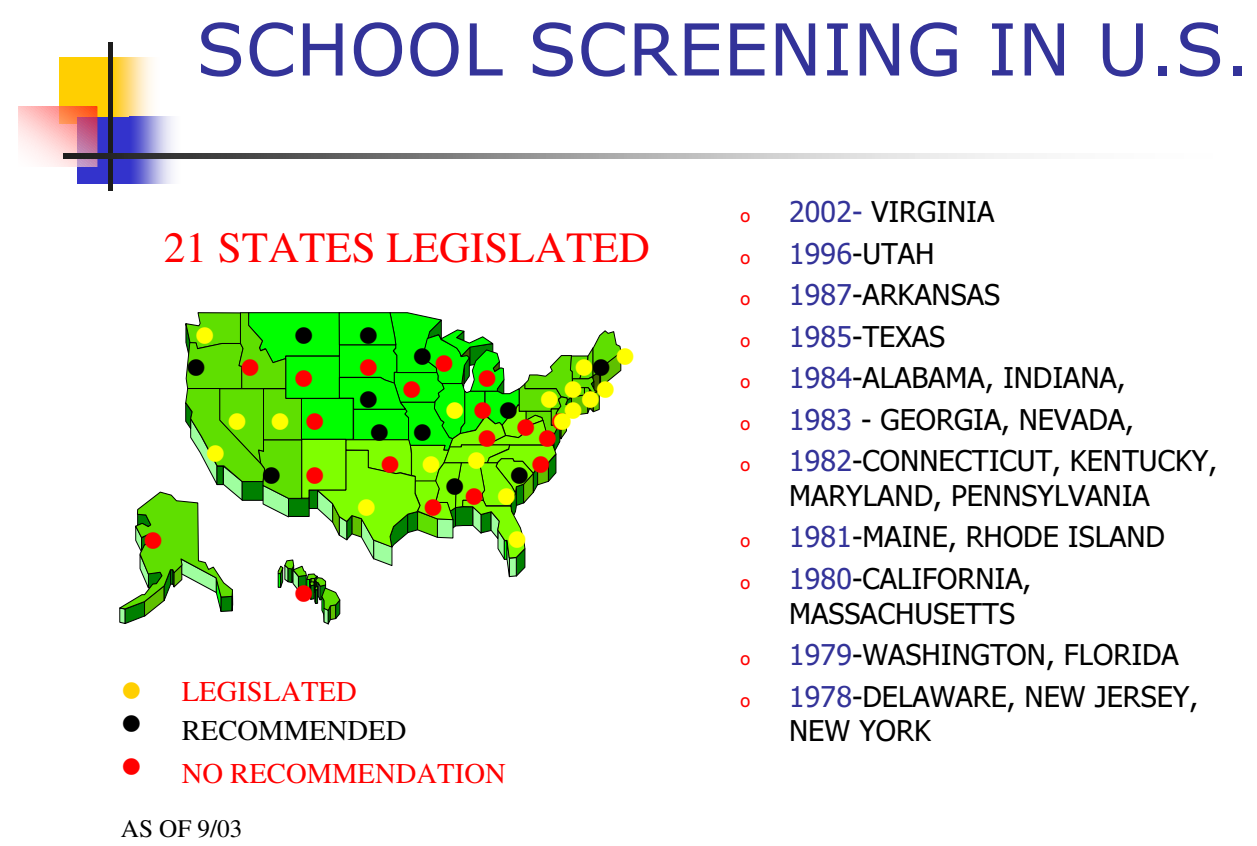

Figure I

School screening in the USA. 
Over-referral of adolescents with insignificant curves led to a marked decrease in many programs, because screening was reported to have a low positive predictive value (0.05 percent). It was demonstrated that over-referral is common, even when multiple diagnostic modalities are used $[164,326]$.

That conclusion was based, in part, on the lack of studies documenting improved outcomes from early identification and treatment of children with scoliosis. While subsequent reports have both supported and questioned the effectiveness of brace treatment for scoliosis $[9,210,220]$, by that time, no randomized, prospective studies have clarified the efficacy of brace treatment.

The American Academy of Orthopedic Surgeons recommends screening girls at ages 11 and 13, and screening boys once at 13 or 14 years of age.

The American Academy of Paediatrics has recommended scoliosis screening with the Adam's forward bending test at routine health visits at 10,12, 14 and 16 years of age, although evidence does not exist to support these recommendations.

In 1996, the U.S. Preventive Services Task Force released its opinion on screening for adolescent idiopathic scoliosis. The Task Force noted that 'there is insufficient evidence for or against routine screening of asymptomatic adolescents for idiopathic scoliosis. [291,330].

Subsequently, in 2004, the US Preventive Service Task Force recommended against the routine screening of asymptomatic adolescents for idiopathic scoliosis. US Preventive Service Task Force changed its recommendation and advised against screening, not on the grounds of new evidence, but by changing the methodology of rating the existing evidence [292,293]!

School screening was introduced sporadically in Australia and to a variable extent in most states and territories. By the early 1990s the cost factor led to the abandonment of most programs in government schools and a new strategy was sought after. The Spine Society of Australia, with the support of the Royal Australian College of General Practitioners, introduced The National Self-Detection Program for Scoliosis. In essence, this entails the distribution of a simple brochure to the target age group (11-13 years of age) in which the outward signs of scoliosis are described. If, after reading the brochure, a girl or her parents think she may have a curvature, then follow-up with the family doctor is recommended. An educational program on scoliosis for general practitioners was also introduced via The Australian Family Physician and is available on the website [335].
This policy resulted in a shortage of recent publications on prevalence studies and therefore in a lack of any research on aetiology in these south latitudes, in contrast to the results and outcome studies that originated from school screening programs from countries located at north latitudes [130].

Studies on aetiology could ultimately help in designing a reasonable aetiological treatment. Recent prevalence studies based on school screening programs, published at least in English language, are also lacking from Africa and South America.

Spurred by the ongoing controversy about this universal and fundamental issue, SOSORT included this consensus paper on school screening in the $4^{\text {th }}$ Society's Meeting in order to study, analyze, understand and finally recommend on school screening.

The following colleagues namely Joseph P. O'Brien, Martha C. Hawes, Toru Maruyama, Stefano Negrini, Manuel Rigo, Elias S. Vasiliadis, Marian H. Wade, Tomasz Kotwicki and Hans Rudolf Weiss contributed in some way to the improvement of the initial questionnaire, which was created by the chairman of this consensus paper. For the full Consensus Paper see Additional file 1.

Before the discussion of this paper at the Boston SOSORT meeting, the questionnaire was completed by 10 colleagues, namely Lorenzo Aulisa, Martha C. Hawes, Toru Maruyama, Stefano Negrini, Manuel Rigo, Elias S. Vasiliadis, Hans Rudolf Weiss, Lior Neuhaus Sulam and Tamar Neuhous, Tomasz Kotwicki and the chairman.

The preliminary results gave an initial impression about the current understanding on the issue. However, after the adjourn of the $4^{\text {th }}$ Boston SOSORT Meeting, 3-7 May 2007, and the end of the relevant consensus paper on the school screening, thirty five completed forms were collected from colleagues representing thirteen countries, namely Austria (one), Canada (one), France (one), Germany (one), Greece (one), Israel (five), Italy (three), Japan (one), Norway (three), Poland (five), Spain (one), UK (four), USA (eight). The results of these completed forms are presented and discussed in this report.

The professions of the attendees were orthopaedic surgeons (six), orthopaedic surgeons and physiatrists (two), rehabilitation doctors (five), physiotherapists and orthopaedic surgeons (two), physiotherapists (nine), nurse (one), C.P.O. (one), various other health care providers (nine).

The Consensus Paper on school screening consisted of 26 questions, see Additional file 1. 
Each question (Q) is deemed with Consensus (100 - 51\% positive answers), with no Consensus (49-0\% positive answers respectively).

For definitions related to screening see Additional file 2.

\section{The primary questions}

Q1 Title: proposed titles of the consensus paper

The first question (Q1) was on the proposed titles of the consensus paper which were:

a) School Screening for Scoliosis. Where are we today? Proposal for a consensus,

b) School Screening and

c) School Screening for posture in Children.

Results: For the $\mathbf{Q} 1$ there were 32 positive answers for the question a (91.4\%), 2 for b $(5.7 \%)$ and one for c $(2.8 \%)$. This point (Question 1 for the title) has Consensus.

Discussion: A point that could be raised with the title is the conformation with a 'consensus.' In fact, in this paper there is no unanimous consensus, but we found, as it will be shown in the next pages, that there are different habits, and experiences, and we do not close with statements that define which consensus we have. Or, better, there is consensus on some answers. Therefore this study is combining the philosophy of consensus and the description of what the widely accepted title is referring to: "School Screening for Scoliosis. Where are we today? Proposal for a consensus." Therefore, this paper is rather a proposal for, not a solid consensus, and also describes the present status on the issue.

Q2 Title: Do you perform a school-screening program for scoliosis at your center?

Results: For the Q2 there were 9 yes (25.7\%), 25 no $(71.4 \%)$ and $1(2.8 \%)$ don't know. Yes (Italy, Greece, Japan, USA), No (Austria, Canada, France, Germany, Israel, Norway, Poland, Spain, UK).

Discussion: This question has no consensus.

Q3 Title: (Is any form of screening for scoliosis performed at your place of work (e.g., organizations, like orphanages, boarding schools, universities, hospitals, factories, offices, etc.)?

Results: For the Q3 there were 12 yes (34.3\%), 21 no (60\%) and 2 don't know (5.7\%). A responder notes also that (the) paediatricians check the childrens' back at 6 (years), 10 (years) and 14 years of age.
Discussion: Looking at Q2 and Q3, it appears that more centres perform school screening at the above countries than was initially believed.

Q4 Title: Has a previously run school-screening program been discontinued at your place of work?

Results: For the Q4 there were 7 yes (20\%), 24 no (68.6\%) and 4 don't know (31.4\%).

Discussion: It is interesting to quote the various comments accompanying the answer to this question like: 'Parents are usually angry when they discover that their child could be diagnosed earlier, before visiting the health provider. Parents are happy with school screening. School screening was a routine and stopped because of money. Parents demand again and again to have it.' 'Screening was interrupted because of the absence of public health administrators' interest.' 'Both parents and school physicians were sorrowful for the interruption of the program that was felt as a good opportunity for the health of the children.' 'In speaking with school nurses in the area who used to participate in screening, their impression was that little follow-up was done in response to their work - even if parents took their children to physicians, the physicians did not recommend follow-up or treatment.' 'We use to see surgical cases at first visit never discovered before, coming only from south Italy. Now we see them also from the north. People with scoliosis are angry at this.' 'Not to my knowledge but I cannot answer this 100\% sure.' '15 years ago there was a school screening as a routine at the ages of $6,10,12-13$, performed by school nurses; since then, because of economic problems, most of the school nurses tasks cancelled, including the posture screening. Today there is no school screening as a routine but here and there it is performed by school doctors or nurses but it is not a law. As a result, there are many cases of late and misdiagnosed and many parents are angry about it. The financial problems in the education system obliged for other priorities.'

Q5 Title: $a=$ Is your center or practice actually screening per the request of a school or public health department, or $b=$ are you doing it on your own as a gesture of good will?

Results: For the Q5), there were 3 readings for a (8.6\%), 10 readings for $\mathrm{b}(28.6 \%), 4$ for both $\mathrm{a}$ and $\mathrm{b}(11.4 \%)$ and 28 don't know (51.4\%).

Discussion: The following comment was reported: 'We tried a few times to perform the screening voluntarily but every time there was objection from some sores.'

This question has no consensus. 


\section{Organization}

There is great diversity in the policies for scoliosis screening worldwide. For example, in the United States there is no nationwide requirement or standard for scoliosis screening; such policies are established at the local state, county, city, or school district level. In some states, scoliosis screening may be done in the pediatrician's office or by a chiropractor or other health care professional, and not in the schools at all. Because scoliosis screening policies are so variable in different parts of the world, we are asking the following questions.

Q6 Title: Is the school screening program compulsory in your country, state or local area?)

Results: For the Q6 (there were 8 yes $(22,85 \%) 26$ no $(74.28 \%)$ and 1 don't know (2.85\%). Yes (Japan), No Italy, USA, Italy, Spain, Greece, Germany, Israel and Poland

Discussion: Therefore there is a vague picture on the issue of school screening in Japan, Europe, North America, but there is no information from Africa, Australia and Latin America.

This question has no consensus.

Q7 Title: Which authorities are responsible for providing permission for school screening in your country?

Results: For the Q7, there were the following answers for the various countries:

Austria, Ministry. Canada, Health Canada. France, Ministry of Health. Germany, Ministry. Greece, Greek Ministry of Education, the Hospital Board of Directors applies to the Greek Ministry of Education for permission to enter the schools and perform the program. Israel Ministry of Education, Ministry of Health and the Head of the School. Italy, local referent. In Italy would be the same as in Greece. Japan, Local Education Committee. Norway, Health Directory of the Ministry of Healthcare. Poland, Ministry and local authorities (also Ministry of Education for permission to enter the schools and perform the program). Ministry of Education, Ministry of health, local department of education in the municipality and the head of the school. Spain, Ministry. UK, Ministry. USA, Ministry, State mandated, Board of education, the Public Health Agencies of the Federal and State.

Discussion: This question has no consensus.

Q8 Title: Who pays for the screening program?
Results: For the Q8 there were the following answers for the various countries:

Austria, Canada, France, Germany, Greece, Indirectly the Hospital, at which the School screening program team is working. Israel, Nobody. Italy, Nobody. Japan, Local educational committee. Norway, Poland, Nobody. Spain, UK, USA, State, Govermment.

Discussion: For the discussion on cost for school screening please see also Q23 [20,124,129,133,206].

This question has no consensus.

Q9 Title: Is the (Orthopaedic) Medical Association of your country or state supporting the school screening program?

Results: For the Q9 there were the following answers for the various countries: Yes $=5(14.28 \%)$, no $=1542.85 \%$, there is no statement on the issue $=5(14.28 \%)$, I don't know 10 (28.57\%).

Discussion: Only 14\% of Orthopaedic or Medical Associations of the participants countries are supporting school screening.

Our recommendation would be the communication with National Orthopaedic or Medical Associations in order to explain the problem to them and convince them to issue a positive statement for school screening examination.

This question has no consensus.

Q10 Title: Would you support a change of the term school screening to postural screening?

Results: For the Q10, there were No $=20$ (57.15\%) and yes $=15(42.85 \%)$.

Discussion: In, many places in the United States the nomenclature for school screening has been changed to Postural Screening, because the exam involves looking at postural deviations to identify the presence of scoliotic, kyphotic, and/or lordotic deformities.

The comments accompanying the answer of this question were very important and indicative for no change, 'as posture can be impaired without deformity, therefore there is a need to search for deformity, and not for bad posture that counts for less than 50\% during school age,' also 'posture pertains to physical education and not health services.' Moreover, 'school screening is a general term and could include many topics and some other screening examinations e.g. epidemiological data, anthropometric measurements, which are extremely necessary in scoliosis research.' 'The term postural screening is restricted to pos- 
tural measurements and thus is inadequate.' It was also stated that 'postural screening is a specialized activity that should be kept to specialist,' or 'school screening is a more appropriate description and everyone knows what it means.'

However, the arguments for a change are also reasonable. They state that it takes the emphasis away from 'school' and may help change the misconception that if the school doesn't do it there is no need for it to be done at all. Also, it helps detection of Scheuermann in boys aged 12-14 years.

This question has no consensus.

\section{Methods and criteria used for school screening: what happens afterwards for children at risk}

Q11 Title: a. who performs school screening currently at your center? and $b$. who do you think would be the most appropriate persons to perform the screening?

Results: For the Q11 a and $\mathrm{b}$, the response from the attendees is described in Table 1.

Discussion: As it appears from the answers of this questionnaire, the school screening performers internationally are currently: SNs $48.57 \%$, PTs 28,57\%, ODs $17.14 \%$, PETs $11,42 \%$, and follow in percentage of involvement RNs, SDs, and HCVs. However, the most appropriate persons to perform the screening were considered to be in descending preference the PTs $77.14 \%$, SNs $51.42 \%$, RNs $28.57 \%$, ODs $22.85 \%$, HCVs $17.14 \%$, and follow in per-

Table I: The school screening performers

\begin{tabular}{|c|c|c|c|c|}
\hline Health care provider & QIla & QIIa (\%) & QIIb & QIIb (\%) \\
\hline $\begin{array}{l}\text { Orthopaedic doctors } \\
\text { (OD) }\end{array}$ & 6 & 17,14 & 8 & 22,85 \\
\hline $\begin{array}{l}\text { Health Care Visitors } \\
\text { (HCV) }\end{array}$ & 1 & 02,85 & 6 & 17,14 \\
\hline Registered Nurses (RN) & 2 & 05.71 & 10 & 28,57 \\
\hline Physical therapists (PT) & 10 & 28,57 & 27 & 77,14 \\
\hline $\begin{array}{l}\text { Physical Education } \\
\text { Teachers (PET) }\end{array}$ & 4 & 11,42 & & \\
\hline School Nurses (SN) & 17 & 48,57 & 18 & 51,42 \\
\hline Other & & & 2 & 05.71 \\
\hline $\begin{array}{l}\text { Combination of } \\
\text { I don't know }\end{array}$ & 13 & 37,14 & & \\
\hline Spine Specialist (SS) & & & 1 & 02,85 \\
\hline School Doctor (SD) & I & 02,85 & & \\
\hline
\end{tabular}

QI la represents the number of answers on the questionnaires for question a. Who performs school screening currently at your center? and QIla (\%) the relevant percentages.

Q I Ib represents the the number of answers on the questionnaires for question $b$. Who do you think would be the most appropriate persons to perform the screening? and QI Ib (\%) the relevant percentages. centage of involvement the SS. PETs were not considered at all as school screening performers.

There is variety in the personnel performing the school screening. The main issue in performing the program is training of the personnel. There are some training programs, like the one of the Arkansas Department of Health, which provide an Instructor Training Course in Scoliosis Screening. This workshop is designed to teach the principles and proper technique for scoliosis screening. Any graduate of this course is a Certified Scoliosis Screening Instructor and is qualified to teach persons to be scoliosis screeners. The certification is valid for a period of five years, after which time an update course in Scoliosis Screening is required for recertification. Recertification is again for a five year period and this cycle continues.

This question has no consensus.

\section{Definitions concerning personnel training}

A. Certified Instructors: Individuals who train the screeners. These shall be licensed health practitioners who have successfully completed (for example the Arkansas Department of Health Instructor) a Training Course in Scoliosis Screening.

B. Screeners: Individuals who perform the actual scoliosis screening. These shall be licensed physicians, individuals who have been trained to perform scoliosis screening by a Certified Scoliosis Screening Instructor or individuals who can document completion of a Scoliosis Screening Workshop within the past five years and demonstrate competence to a Certified Scoliosis Screening Instructor level $[11,336]$.

Q12 $a$ and $b$ Title: a) What is the sex and age range of those screened at your center? b)Please indicate below the respective sexes and age ranges that you think should be screened.

Results: For the Q12a and Q12b answers see Table 2.

Discussion: The development and mainly the progression of adolescent idiopathic scoliosis (AIS) are related in girls to the appearance of menses. This biological milestone does not always appear at similar ages in girls living in different geographical latitudes. Therefore, the age ranges that should be screened must be in accordance with this variation. However, if it is feasible to screen wider age ranges, then the collected information could give valuable aetiological clues, more reliable longitudinal data and a consequent improvement of our insight to the pathophysiology of AIS. Considering that there are no sufficient epidemiological data in the literature for the prevalence of idiopathic scoliosis in several geographical areas and the natural history is not yet accurately predictable, we can 
Table 2: Sex and age range of those screened currently

\begin{tabular}{|c|c|c|c|c|}
\hline Age girls & QI2a & QI2a (\%) & QI2b & QI2b (\%) \\
\hline Younger than 7 years of age & $\begin{array}{l}4-14 \text { years }=1 \\
5-10 \text { years }=1\end{array}$ & & $\begin{array}{l}4-14 \text { years }=1 \\
5-15 \text { years }=1 \\
5,6 \text { years }=2\end{array}$ & \\
\hline 7 years & 6 & 17,14 & 7 & 20,00 \\
\hline 8 years & 4 & 11,42 & 6 & 17,14 \\
\hline 9 years & 5 & 14,28 & 13 & 37,14 \\
\hline 10 years & 8 & 22,85 & 19 & 54,28 \\
\hline II years & 7 & 20,00 & 20 & 57,14 \\
\hline 12 years & 11 & 31,42 & 19 & 54,28 \\
\hline 13 years & 7 & 20,00 & 17 & 48,57 \\
\hline 14 years & 7 & 20,00 & 7 & 20,00 \\
\hline 15 years & 2 & 05,71 & 4 & 11,42 \\
\hline Older than 15 years & 2 & 05,71 & 1 & 02,85 \\
\hline All school ages & & & I & 02,85 \\
\hline No answer & 17 & $48,57 \%$ & & \\
\hline Age boys & $Q \mid 2 a$ & QI2a (\%) & QI2b & QI2b (\%) \\
\hline Younger than 7 years of age & $4-14$ years $=1$ & & $\begin{array}{l}4-14 \text { years }=1 \\
5-17 \text { years }=1 \\
5,6 \text { years }=2\end{array}$ & \\
\hline 7 years & 6 & 17,14 & 6 & 17,14 \\
\hline 8 years & 5 & 14,28 & 5 & 14,28 \\
\hline 9 years & 6 & 17,14 & 5 & 14,28 \\
\hline 10 years & 9 & $25,7 \mid$ & 10 & 28,57 \\
\hline I I years & 7 & 20,00 & 12 & 34,28 \\
\hline 12 years & 10 & 28,57 & 17 & 48,57 \\
\hline 13 years & 6 & 17,14 & 19 & 54,28 \\
\hline 14 years & 7 & 20,00 & 15 & 42,85 \\
\hline 15 years & 2 & 05,71 & 8 & 22,85 \\
\hline Older than 15 years & 2 & 05,71 & 2 & 05,71 \\
\hline All school ages & & & I & 02,85 \\
\hline No answer & 17 & $48,57 \%$ & & \\
\hline
\end{tabular}

Q I2a represents the number of answers on the questionnaire for question a. What is the sex and age range of those screened at your center? and $\mathrm{Q} I 2 \alpha(\%)$ the relevant percentages, while Q I $2 \mathrm{~b}$ represents the number of answers on the questionnaire for question $b$ Please indicate below the respective sexes and age ranges that you think should be screened, and QI $2 \mathrm{~b}(\%)$ the relevant percentages.

assume that school screening is not only an instrument for early detection and decrease in the number of adolescents that will eventually experience operative treatment, but is also a priceless tool for research on scoliosis aetiology [121-123,125-127,130,172,173,262,263,270,271].

This question has no consensus.

Q13 Title: Is a scoliometer used during the screening examination at your center?

Results: For the Q13 there were the following answers: Yes $\mathrm{n}=23(65.71 \%)$, no $\mathrm{n}=3(08,57 \%)$, I don't know $\mathrm{n}=9$ $(25,71 \%)$.

Discussion: The Bunnell scoliometer is widely used (by 19 users). The Prujis scoliometer (by 2 users) is also used. The recommendation is the use of a scoliometer for the performance of school screening.

Question 13 has consensus.

Q14 Title: While performing the forward bending test (FBT), in what position is the scoliometer measurement taken *?

Results: For the Q14 Standing FBT n = 17 (48,57\%), Sitting FBT $n=4(11,42 \%)$, Prone non, both Standing FBT and Sitting FBT $n=6(17,14 \%)$.

Discussion: * The standing forward bending test (FBT) traditionally refers to the Adams Forward Bending Test; however, some additional body positions have been utilized recently, i.e., the sitting or prone positions. For this reason, we are herein substituting the terms Standing FBT, 
Sitting FBT or Prone Position for the Adams Forward Bending Test.

All screening techniques depend on surface topography. The Adams forward bending test is well known to school and primary health care personnel and widely used to provide a subjective or qualitative evaluation of spinal deformity. The application of physical measurements provides a quantitative evaluation of deformity and the basis for objective referral criteria for screening, which substantially increases its effectiveness [10].

In the standing forward bending position, the student is asked to bend forward looking down, keeping the feet approximately $15 \mathrm{~cm}$ apart, knees braced back, shoulders loose and hands positioned in front of knees or shins with elbows straight and palms opposed.

Many devices and techniques have been used, including measurement of the rib hump height using a level and ruler, stereophotogrammetry, flexicurve, ultrasound, thermography, back contour devices, etc. Moiré topography, a photographic method, and computerized surface mapping systems such as the Integrated Shape Imaging Systems (ISIS) have been studied extensively and provide the most complete description of surface topography. The time and expense required to do these studies make them impractical for mass screening. Inclinometry [measurement of the angle of trunk rotation (ATR) observed with the patient in the forward bent position] seems to be the simplest, quickest, most reliable, and least expensive objective measurement of trunk deformity. One useful device, the scoliometer (Orthopaedic Systems, Inc., Union City, CA), has achieved widespread usage with numerous reports of its reliability. None of these techniques is diagnostic. Radiographs are required to establish the diagnosis, aetiology, and severity of spinal deformity $[4,6,43,45,74,135,164,172,190,247,289]$.

This question has no consensus, even thought it is close to it.

Q15 Title: Are any signs of maturity documented while screening?

Results: For the Q15 There were Yes $\mathrm{n}=7$ (20.00\%), No $\mathrm{n}$ $=15(42,85 \%)$ and no information $\mathrm{n}=13(37 \%)$.

Discussion: It was reported that the menarche state, only if the patient is scoliosis positive, is the only documented sign of maturity.

This question has no consensus.
Q16 Title: Has your center encountered non-cooperation or refusal of the screening examination from children or their parents?

Results: For the Q16 there were Yes $\mathrm{n}=3(8,57 \%)$, No $\mathrm{n}=$ $15(42,85 \%)$, no information $n=17(48,57 \%)$.

Discussion: The responders reported that 2\% refused school screening. This should be considered an acceptable rate, as many children are present at the following year's screening. It was also reported that the encountered difficulties in performing the school screening were not usually the non-cooperation or refusal of the screening examination by parents but mainly the negative attitude from mainly older children. The parental refusal was included in the consent form filled earlier by them. The examiners can usually do nothing about it.

Q17 Title: Over which ATI (Angle of Trunk Inclination) or ATR (Angle of Trunk Rotation) is a hospital consultation and/ or radiographical examination recommended?

Results: For the Q17 the response was:

More than 4 degrees of ATI/ATR $\mathrm{n}=1(2,85 \%)$, more than 5 degrees of ATI/ATR $n=10(28,57 \%)$.

More than 6 degrees of ATI/ATR $n=8(22,85 \%)$, more than 7 degrees of ATI/ATR $n=2(05,71 \%)$.

More than 8 degrees of ATI/ATR $n=1(2,85 \%)$, other: Scoliometer exam by itself is not enough to decide, no information $\mathrm{n}=13(37,14 \%)$.

Discussion: For the discussion of this question see also questions 13,18 and 20.

This question has no consensus.

Q18 Title: Where are those who need to be referred sent for further assessment?

Results: For the Q18 the response was:

To our hospital $n=7$ (20\%), to any specialized outpatient department of any hospital in our city/state/country $n=6$ $(17,14 \%)$, to our private practice $\mathrm{n}=4(11,42 \%)$, to our hospital or to any specialized outpatient department of any hospital in our city/state/country $n=1(2,85 \%)$, to any specialized outpatient department of any hospital in our city/state/country or to our private practice $n=2$ $(5,71 \%)$, to no one; the family is sent a note which encourages them to schedule a visit with their pediatrician $\mathrm{n}=1(2,85 \%)$, to the primary physician $\mathrm{n}=1(2,85 \%)$, to 
an orthopaedic doctor $\mathrm{n}=1(2,85 \%)$, to family doctor $\mathrm{n}$ $=1(2,85 \%)$.

Discussion: The AAOS and the SRS maintain that not all children who are referred because of a positive screening result require radiography [7]. By design, school screening will refer some children who do not have scoliosis in an effort not to miss referring children with scoliosis. The question of when to obtain radiography cannot be answered on the basis of available scientific data. It is recommended that it is likely to obtain radiographs in children who have (1) a large, unambiguous curve on physical examination, (2) asymmetry on examination in skeletally immature children (the risk of curve progression is greatest during growth), (3) asymmetry on examination and a family history of scoliosis, and (4) asymmetry and neurologic signs or symptoms [9]. The scoliometer threshold reading of 7 degrees or more is used by the majority of practitioners, [122]. It appears, however, that age and growth play an important role in the agreement of scoliosis surface and radiological deformity $[131,132]$.

This question has no consensus.

Q19 Title: Please describe the treatment offered to those referred from the screening program:

Results: For the Q19 the response was:

Observation, with timing and frequency thereof: (three times a year, or three months during growth spurt), Exercises, and when prescribed: (if possible defect exist), Brace treatment, and when prescribed: $\left(25^{\circ} \mathrm{Cobb}\right.$ angle, progressed curves, and depend on the case and doctor, above $25^{\circ} \mathrm{Cobb}$ and immature, According to Italian guidelines [214,311,312].

Discussion: This question has no consensus.

Q20 Title: Please fill in this table with data from your screening experience (if available):

Results: For the $\mathbf{Q} 20$ the response was:

a. Number of people screened: in the year(s)

b. Percentage ofscoliosis detected in the screened sample:

ATR threshold for scoliosis detection:

c. Percentage of patients radiographed:
ATR threshold for radiographic prescription:

d. Percentage of patients with prescription of exercises:

e. Percentage of patients with prescription of a brace:

g. Percentage of patients with prescription of surgery:

In this question we are quoting the teams' response screened $\mathrm{n}=1000$ or more students.

Number of people screened: 15000 in the year(s) 1983-1994.

Number of people screened: 10000 in the year(s) 1997-2006.

Number of people screened: 9995 in the year(s).

Percentage ofscoliosis detected in the screened sample $7 \%$.

Percentage ofscoliosis detected in the screened sample: $2.9 \%$.

Percentage ofscoliosis detected in the screened sample: $2 \%$.

ATR threshold for scoliosis detection: 4.

ATR threshold for scoliosis detection: $\geq 7$ degrees.

ATR threshold for scoliosis detection: $5^{\circ}$.

Percentage of patients radiographed: $80 \%$.

Percentage of patients radiographed: 3.5\%.

Percentage of patients radiographed: .2\%.

ATR threshold for radiographic prescription: $5^{\circ}$.

ATR threshold for radiographic prescription: $\geq 7$ degrees.

ATR threshold for radiographic prescription: $5^{\circ}$.

Percentage of patients with prescription of exercises: $80 \%$.

Percentage of patients with prescription of exercises:

Percentage of patients with prescription of exercises: 
Percentage of patients with prescription of a brace: $10 \%$.

Percentage of patients with prescription of a brace: $0.3 \%$.

Percentage of patients with prescription of a brace: $1 \%$.

Percentage of patients with prescription of surgery: $0 \%$.

Percentage of patients with prescription of surgery: $0.03 \%$.

Percentage of patients with prescription of surgery:

Discussion: The responses pertained to children screened and not to known patients (i.e. scoliosis already screened).

Q21 Title: Do you believe that school screening is useful for clinical purposes, i.e., does it affect the age at which scoliosis is treated?

Results: For the Q21 there were Yes $\mathrm{n}=31(88,57 \%)$, No $\mathrm{n}=0(0 \%)$, Not sufficient data $\mathrm{n}=1(2,85 \%)$, not sure $\mathrm{n}$ $=1(2,85 \%)$

Discussion: This question has consensus.

Q22 Title: Do you believe that school screening is a valuable undertaking, even though the aetiology of idiopathic scoliosis is not yet clear and an aetiologically-based treatment has not yet been established?

Results: For the Q22: Yes $\mathrm{n}=31(91,42 \%)$, No $\mathrm{n}=1$ $(2,85 \%)$.

Discussion: The reasons given were numerous: 'to determine prevalence in the population, and to direct patients to appropriate care'; 'it is not a big price to find and save one boy from school and save from surgery'; 'an early effective treatment will minimize progression and therefore reduce the number of surgeries and number of people with severe curves'; 'it would ensure more favorable outcomes and reduce deformity, minimize surgery and would make economic sense'; 'epidemiology data, early treatment effectiveness'; 'early detection improves final results'; 'enables an early diagnosis of the disease and an early treatment'; 'besides its clinical usefulness, it is a valuable research tool.'

A more eloquent report is adduced because it beautifully analyses the issue: "If screening is eliminated, we will return to the old days when the 'usual time of diagnosis' [203] is forty degrees or more, an obvious deformity is present, and surgery can be justified without further ado. Otherwise, citizens suffering from mild or moderate spinal deformity will continue to remain in the dark about the possible basis for their pain, pulmonary limitations and psychological problems. The current absence of any meaningful therapies for spinal deformity through the medical community does not make screening 'unethical,' as Dickson and Weinstein [80] have proposed. Instead, this situation makes it all the more important that patients be in a position to help themselves. The only legitimate reasons not to screen for a condition with the potential to cause a lifelong struggle with a range of health problems are (1) To avoid overexposure to X-rays, and (2) To avoid overtreating children with traumatic interventions of dubious clinical value, like bracing and spinal fusion surgery. These dangers are restricted to the context of current approaches as applied in this country. Given the limitations of the Cobb angle for judging spinal deformity in a meaningful way, ongoing work by some researchers to establish more appropriate and less destructive clinical assays perhaps is the most critical area of needed research [115,331,337-344]."

It was also stated by another responder that current knowledge about scoliosis and conservative management thereof is not enough among the general body of specialists to take advantage of early detection. Lack of knowledge is related to misleading information reaching the patients and their families, abuse of non-effective therapies, abuse of invasive tests (X-ray) and finally over-treatment. However, this situation could be alleviated by education provided by specialists from, for example, the SOSORT and ultimately the situation could be reverted: right information, effective light therapies, X-ray only when necessary and prevention of under-treatment.

The negativists are stating that 'cost too much,' 'most of the cases that we treat from below 20 Cobb under 12 years, more than $99 \%$ do not come to surgery.'

The current knowledge is that early recognition of the disease and appropriate conservative treatment, when indicated, changes the natural history of idiopathic scoliosis. There is adequate evidence in the literature to support this statement [345-356]. Torell et al [285], evaluated the effect of a program for early detection and treatment of idiopathic scoliosis in a stable population of 1.5 million over a ten-year period. Seven hundred and twenty-five patients with a scoliosis of more than 20 degrees (as measured with Cobb's method) and aged twenty years or younger were followed during that period. Although treatment principles remained essentially the same, the percentage of patients who required an operation decreased each year. The magnitude of the ten most severe curves detected each year decreased from an average of 64 degrees to 44 degrees. Efforts to detect scoliosis early have resulted in a threefold increase in the number of patients treated for scoliosis [285]. 
Korovesis et al. [171], in a prospective study of the effect of TLSO on spinal deformities, indicated that TLSO treatment halted the progression of scoliosis and reduced the number of patients requiring surgery, thus changing the natural history of the disease.

Nachemson et al. [210] described the results of a prospective multi-centre analysis of 286 girls with AIS and documented that bracing altered the natural history by preventing curve progression.

Rowe et al. [245], in a meta-analysis of 37 peer-reviewed articles on conservative treatment of scoliosis, found that 23-hour bracing was the most successful means of halting progression of scoliosis; the Milwaukee brace was found to have the highest rate of success in comparison to electrical stimulation.

The beneficial results of the brace on the natural history of the above curves were also described by Valavanis et al. [294]. The results and the reliability of the brace were subsequently checked and confirmed by Grivas et al. [128].

Therefore it is evident that bracing prevents about $20 \%$ to $40 \%$ of appropriately braced curves from progressing $6^{\circ}$ or more [17].

This point (Question 22) has Consensus

Q23 Title: Do you believe that the concept of cost-benefit analysis should be applied to screening?

Results: For the Q23 there were Yes, $\mathrm{n}=17(48.57 \%)$, No $\mathrm{n}=15(42,85 \%)$, Don't know $\mathrm{n}=2(5,71 \%)$.

Discussion: The reasons given for yes:

a) Unfortunately in our country we have limited resources for both education and health care. Therefore, benefits of screening must be weighed against costs.

b) For evaluation purposes.

c) As a medical doctor I would like to say NO, but this would be too idealist and I think the world cannot go on without the application of cost-benefit analysis, when public funds are used. However, any program supported exclusively by NGO could be done without the application of this concept.

d) Undetected cases $>30^{\circ}$ are rare, however physicians should know more!

e) Yes but not exclusively and not decisively.
The reasons given for no:

a) Because scoliosis can have profound effects on individual's life.

b) First I think about the individual, the public system doesn't take into consideration the one boy or girl who needs the treatment.

c) Again one saving, one avoid the surgery, will equal a screening.

d) In the end, the reduced number of surgeries and scoliosis back pain-related treatments will save the government more money than screening would cost.

e) If 1 or 2 local children per year have the option to avoid surgery, this is a justification for the program.

f) I think cost-benefit analysis is meaningless given the absence of tracking, standards, and follow-up of patients. Thus, for example, a single patient who receives multiple revision surgeries costing hundreds of thousands of dollars skews all analyses and none of these are considered in 'cost-benefit' analysis.

g) Because the cost of a late treatment surpasses the cost of an early treatment.

h) You have to try to do it at low cost.

j) You cannot apply cost-benefit principles to research that originate from school screening.

k) The one case that can be saved from surgery has a 100\% success rate for that particular case.

1) Early detection implies early treatment and by that less surgery. Thus, increased costs at an early stage may decrease later costs $[133,184,206,285]$.

As a common thinking, in order to achieve reasonable cost effectiveness, the number of false-positive referrals must be reduced and minimize the cost and radiation of the smaller curves [67].

For definitions related to direct and indirect school screening cost, the reader is referred to the definition section.

A realistic evaluation of both direct and indirect costs is not feasible and could result in inaccurate overestimation of the total cost as it might take into consideration many qualitative and subjective factors, such as the definition of scoliosis, the threshold for referrals for radiological evalu- 
ation, indications for conservative and operative treatment, cost to the society, children's compliance, decisions of the clinicians, effectiveness of treatment and impact on children's quality of life $[20,133,179,285]$.

The negativists of school screening implicate the increased indirect cost and the psychological impact on the child, which basically cannot be measured, to criticise these programs. However, they are not discussing about the cost of the child's and his/her family psychological stress when a severe, untreated curve is discovered, or the cost of the child's and family's psychological stress when they are led to the operating room, or even what the feeling of an operated scoliotic is, with a rod in her back holding him/her straight. No one has given a frank answer on this issue so far. As Dr. Bunnell characteristically reports, 'we're not looking for the cheapest way to screen - we're looking for a better quality outcome for our patients'. Additionally, we must be motivated and guided by an ancient Greek saying, according to which 'it is better to prevent than to treat'.

This point (Question 23) has no Consensus.

Q24 Title: Do you believe that school screening is useful for academic purposes, i.e., do we learn about scoliosis from school screening?

Results: For the Q 24 there were Yes n $=26$ (74,28\%), No $\mathrm{n}=2(5,71 \%)$, I don't know 7 (20\%).

Discussion: The reasons given for No were:

a) The big problem is adolescent scoliosis, b) not the prevalence, but progression rate in the long-term is important, c) previous research has shown it not to be beneficial, so why continue.

In cases of yes, it was further asked to describe the knowledge that has been acquired thus far or that can be advanced from the performance of school screening:

The reasons given for yes were:

a) Prevalence of AIS school children.

b) Increase in the understanding of scoliosis.

c) Statistical analysis.

d) Teach MDs.

e) It will provide a more accurate understanding about the age scoliosis appears at - rather than taking onset as the time of detection or first diagnosed data. d) It would be more helpful if accompanied by a demographics history form.

e) Prevalence of scoliosis.

f) students learn about scoliosis.

g) Most of what we have learned about incidence is based on school screening.

h) Prevalence, early detection, prevention of progression.

i) Research on natural history and aetiopathogenesis could be designed much better.

j) Knowledge of scoliosis incidence, influence of genetic or environmental factors in scoliosis aetiology.

k) Perform longitudinal studies.

1) How form and function change with the development of scoliosis.

m) We can study epidemiology of scoliosis.

n) The results of school screening programs provide valuable data regarding the prevalence and the natural history of idiopathic scoliosis.

o) The benefits of scoliosis screening include increased public awareness of and knowledge about epidemiology and natural history of scoliosis.

p) Considering that there are no sufficient epidemiological data in the literature for the prevalence of idiopathic scoliosis in several geographical areas and the natural history is not yet accurately predictable, we can assume that school screening not only is a means of early detection and diminution of the number of adolescents that will eventually experience operative treatment, but it is a priceless tool for research on scoliosis aetiology as well $[9,45,121-123,125-127,172,173,179,184,237,262,263$, $270,271]$.

Question 24 has Consensus.

Q25 Title: What do you think of exploring the prevalence of scoliosis throughout the lifespan?

Results: For the $\mathbf{Q} 25$ Yes, it would be useful to explore the prevalence of scoliosis throughout lifespan. $\mathrm{n}=20$ $(57,14 \%)$, No, it would not be useful to explore the prevalence of scoliosis throughout lifespan. $\mathrm{n}=7(20 \%)$, I don't know 7 (20\%). 
Discussion: It was thought that by asking only about the utility of screening adolescents, we might miss an opportunity to expand the scope of our communal thinking about scoliosis screening. Although numerous studies suggest that the prevalence of scoliosis is much higher in the elderly population than among adolescents, epidemiological studies to date have focused almost exclusively on paediatric populations. Given the potential toll of a progressive asymmetrical deformity on the ability of elderly people to maintain their balance and avoid falls, it would appear that an expansion of our focus to include some exploration of the prevalence of scoliosis throughout lifespan would be justified [231,254].

The comments for Yes were:

- Because it is a chronic illness.

- Scoliosis progresses through life especially for women. People with scoliosis tend to have many back problems and pain as they age.

- Because functional scoliosis can become structural and greatly impact quality of life.

- I have no knowledge about this but see adults with scoliosis secondary to osteoporosis. I believe adults should do similar screening every year.

- At our clinic we are contacted by many elderly people whose scoliosis has either never been detected or is lateonset.

- I think there are many adults suffering from scoliosis with no one to help them.

- Scoliosis at any age is functional and reversible in its early stages, its appearance has aetiological implications for children and grandchildren and it makes no sense to avoid diagnosis and education.

- This is one of the most effective tools to check when prevention policies are effective.

- It would be useful to investigate to what percentage adult scoliosis is different from idiopathic scoliosis of adolescents and is not caused by degenerative spinal disorders or segmental spinal instability.

- If a high prevalence of scoliosis throughout lifespan will be found, the health community should research and learn more about scoliosis, in order to treat functional problems and back problems.

The comments for No were:
- No need to treat these patients unless they have symptoms, in which case they will visit a doctor.

- The big problem is adolescent scoliosis.

- Not prevalence, but progression rate in the long-term is important.

- Screening of adolescents is useful to prevent the deformity. In the elderly, treatment is reserved only for symptomatic curves that do not need a screening program.

- The problem is how (there are no problem places where you find the entire population like schools) and consequently who and where.

- We know about scoliosis 'de novo' in adulthood, so what more?

- It is not useful to explore the prevalence of scoliosis throughout the lifespan. Pain is the primary sign and will bring the patient to the doctor; deformity will be diagnosed on this occasion.

This Question 25 has Consensus.

Q26 Title: Please add any issue relevant to the survey or any question that you consider to be important and think should be added to the questionnaire.

Results: For the $\mathbf{Q} 26$ there were the following suggestions and/or comments:

- I am glad that the SOSORT is looking at the issues of screening in both the childhood and adults

- a) Screening b) Spine specialist consulting for moderate to severe scoliosis. I work outside the government and medical systems. I only know about screening through my students. This survey was difficult for me to respond to. Some Yoga teachers are highly trained in postural analysis and may be helpful resource for performing the screening.

- It is very important to decide how to do the screening. One by one in the 'hung room' or in the middle of the class? Take shorts off or not? Ask the child about pain or other subject?

- I believe that school screening should be compulsory in all countries - as we can only come to fully understand the complicities of scoliosis

- I would like to see school screening in the UK

- It seems to me better to improve the school nurse. 
- In families or individuals with known risk factors (there are hundreds - including childhood surgery or trauma, birth injuries, familial disorders with a high prevalence of scoliosis, infections, spinal injuries, etc), screening for scoliosis should occur routinely and often throughout life, and research to develop simple, nondestructive methods to reverse curvatures before they become deformities, needs to be a high priority.

- In the 5 years after beginning screening (1988-1999) there has been only 1 surgical treatment in this area for scoliosis.

- At least 3 years in girls and boys differently have to be evaluated, because no one really knows when the growth spurt will start. And when it starts, 12 months' time can be too late (I have seen $5-50^{\circ}$ in 3 Months!). Which means, in order to be on the safe side, 11-13 (maybe 10 years) year old girls and 12-14 year old boys should be screened every 3 months; does anybody find that reasonable?

\section{The impact of scoliosis school screening on frequency of surgical treatment}

The earlier data reported on this issue appear to be in some way inconsistent and inconclusive. For example, in Minnesota, USA, a place with school screening in practice, a decreasing frequency of IS surgery was found, beginning in 1974 and continuing through 1979, the last year reported, [184]. Torell et al. [285] reported that scoliosis school screening, (SSS), reduced the number of surgically treated IS patients.

In a different report [11], data on the frequency of surgical treatment per thousand children screened for 7 or more years, were disclosed from three US states: Kansas and Virginia showed no clear trend. For Minnesota, the frequency of surgery was decreasing until 1981-82, after which it increased [11].

Some more recent European reports are more convincing on the impact of conservative treatment on the frequency of surgical treatment of IS. The incidence/prevalence of surgery can significantly be reduced where high-standard conservative treatment is available $[189,239,314,345-$ 356].

\section{The impact of discontinuation of scoliosis school screening}

The consequences of discontinuation of school scoliosis screening programs on the referral patterns of AIS patients remain unknown. A recent cross-sectional study was conducted of all patients referred for suspected adolescent idiopathic scoliosis (AIS) for an initial visit to the orthopaedic outpatient clinic of a metropolitan paediatric hospital in Canada [25]. The objective was to document the appropriateness of current referral patterns for AIS in comparison to those that prevailed before discontinuation of school screening in Canada. Of the 489 referred cases, suspected of having AIS, 206 (42\%) had no significant deformity (Cobb angle $<10$ degrees) and could be considered as inappropriate referrals. In subjects with confirmed AIS, 91 patients (32\%) were classified as late referrals with regards to brace treatment indications. The authors conclude that current referral mechanisms for AIS are leading to a suboptimal case-mix in orthopedics in terms of appropriateness of referral [25].

The fact is that this was widely expected and the triumph of epidemiology over early diagnosis was in reality a disaster. Prevention must be a standard policy in civilized societies with medical systems caring about people's wellbeing and not about statistics, epidemiology or only money. We always have to remember what the axiom in the cradle of western civilization, ancient Greece, was. Ancient Greeks used to say that 'metron of everything is man'; the measure, in other words, of appraising everything is only the human being, nothing else.

\section{Why we must continue school screening programs}

It is reported [145] that the policy not to screen because of lack of cost effectiveness is based on the obsolete assumption, derived from an early study [255], that surgery is the only proven treatment option. As pointed out by Hawes [145], the cited study does not justify scientifically this conclusion. Today there is evidence that signs and symptoms of scoliosis can indeed be changed after the application of an intensive in-patient exercise programme [311], and that the rate of progression can be reduced significantly [313]. Furthermore, the incidence/prevalence of surgery can significantly be diminished where conservative treatment is available at a high standard $[189,239,314]$. It has also been documented and is generally accepted that bracing does alter the natural history of idiopathic scoliosis $[17,128,171,210,245,285,294,357]$ and school screening does reduce the number of surgically treated IS patients, as discussed above [285].

Studies on psychosocial health and body image have revealed that functioning in these domains may affect compliance behaviour and satisfaction with treatment outcomes among adolescent patients. Psychosocial and body image disturbance is less marked in patients with good social or family functioning, or patients who exercise regularly or are psychologically healthy [284].

Taken together, these studies support the hypothesis that school screening is justified to allow to detect mild and reversible spinal curvatures and treat them conservatively 
before they develop into spinal deformities with a potential to cause symptoms throughout life [146].

By no means should we aim at replacing school screening by costly methods of gene screening; these are probably useful in predicting curve progression but concordance is far less than $90 \%$ in monozygotic twins and phenotypic variability seems to be very high $[166,310]$.

\section{The evolving aim of scoliosis screening}

The goal of scoliosis screening is to detect scoliosis at an early stage, when the deformity is likely to go unnoticed and there is an opportunity for a less invasive method of treatment, or less surgery, than would otherwise be the case $[70,184,206,285]$.

What in reality scoliosis school screening program does, using the scoliometer or any other surface measuring device, is reveal children with surface, mainly thoracic surface, deformity. It does not reveal the scoliosis per se. It is now definitely accepted that the surface deformity does not accurately predict the magnitude of scoliosis, especially in younger children. As Bunnell characteristically states [45], 'it has become apparent from many reports that, although there is a significant correlation between clinical deformity and radiographic measurement, the standard deviation is so high that it is not possible to reliably predict the degree of curvature from surface topography in any given patient by any technique'. It has also been reported that, in typical screening settings where the prevalence and positive predictive value are relatively low, for every curve $>10^{\circ}$ detected, there are 1-5 false-positives; similarly, for every curve $>20^{\circ}$ detected, there are 3-24 false-positives [131,132,134,291].

The above described phenomenon of over-referrals from school screening programs is the cause of the burden and of the ongoing controversy over its application. Therefore, it must be widely accepted that, with school-screening programs, a chance is mainly given to the school-aged population to rule out those who will be at risk for developing scoliosis, rather than discover those who definitely have scoliosis. This is especially true if there is a significant surface deformity justifying the central axis (that is the spinal) deformity. There is something else that must be highlighted and clearly understood. The school screening program aims at detection of surface deformity and/or the existing number of scoliosis cases; it does not aim at predicting which scoliotic curves will progress to a type that will require some type of conservative or surgical treatment. The criteria used to predict progression of a small or moderate curve are unfortunately not related to school screening programs. All asymmetric children, therefore, who will be entitled to develop scoliosis will miss the opportunity to be picked up and will probably be discov- ered too late, when surgery will be the only treatment option. As expected, the outcome will be particularly worse in poor societies. Therefore, in explaining the role of school screening, it must also be clearly understood that its cost must be the direct cost of performance of the actual screening program and not the subsequent expenditures of follow-up, radiographs and other modalities described in the current literature $[44,133]$.

\section{Recommendations for improvement of school screening procedure}

In addition to our recommendations stated in the discussion of the pertinent questions, Dr Bunnell's recommendations $[44,45]$ for improvement of the school screening procedure are also quoted here.

Recommendations for improvement include redefinition of what actually constitutes a 'significant' scoliosis for screening, diagnostic, and outcome purposes; selective screening of only immature females; the use of objective referral criteria; and re-screening patients rather than referring borderline cases [358].

Dr Bunnell claims that spinal screening programs must have defined referral criteria and "treatment-eligible" degrees of scoliosis, in order to judge their effectiveness. The ideal criteria will minimize both the number of referrals and the number of false-negative examinations. In view of the new prevalence data from his study and the current recommendations to wait until scoliosis approaches 30 degrees (Cobb angle) before starting brace treatment, he recommends changing the screening referral criterion to seven degrees ATR at any level of the spine and changing the definition of false-negative (treatment-eligible curves that are missed) to 30 degrees Cobb angle for the purposes of spinal screening. Under these recommendations, it is anticipated to accomplish a referral rate of $3 \%$ and detect $95 \%$ of all "treatment eligible" curvatures, thus preserving an acceptably low false-negative rate and helping maintain cost effectiveness of spinal screening programs. For youngsters whose curves are below the "treatment eligible" line - for example between 20 and $25^{\circ}$, a repeat screening is recommended within six to twelve months. Repeat screening would take place at school, thus keeping it a public health issue. In conclusion, Dr Bunnell states that 'screening is vitally important, but we do not want to screen out a whole bunch of people who don't need medical attention because it's very costly. We're not looking for the cheapest way to screen - we're looking for a better quality outcome for our patients.'

Grivas et al. [359], by reviewing the collective experience of the "Thriasio" school screening program, provide specific evidence-based recommendations for the improvement of school screening effectiveness. 
School screening has to be set up on a district basis and held by a team of experienced examiners who will organize and prepare everything well in advance. All the interested parties must be informed by distribution of informative material and lectures. Prior to the visit of the examining group to the school, the parents must fill out a consent form and the pupils must fill out a particular form regarding their personal and demographic data.

The regression curve of both the IS prevalence and age at menarche by geographical latitude is following a parallel declining course, especially in latitudes northern than 25 degrees; this means that in northern latitudes, girls experience late age at menarche and higher prevalence of IS. IS almost always occurs during the time of peak growth velocity, typically during the year just prior to menarche. Therefore, in order to increase the predictive value of school screening, we should screen girls who live in northern countries at an older age range than those who live in the south.

By screening children in the sitting position with the use of a scoliometer, we can dramatically decrease the number of referrals, because we eliminate the effects of leg length inequality and pelvic obliquity on the spine. Sitting position reveals the true trunk asymmetry which could be associated with IS and therefore is recommended as a standard examination method in a school screening program.

The referral process must be standardized according to a specific protocol by documenting all the prognostic factors for progression of a detected curve. As a second stage of screening, demographic and clinical parameters, including the gender, the chronological age, the age at menarche, the pattern and the magnitude of asymmetry and the growth potential must be recorded, in order for the more experienced Orthopaedic surgeons to determine whether it is necessary to $\mathrm{x}$-ray a referred child or not.

Approximately $25 \%$ of younger referred girls (aged $<13$ years old) with an ATR $\geq 7^{\circ}$ were found to have either a straight spine or a spinal curve under $10^{\circ}$. In this age group the correlation between clinical deformity and radiographic measurement is not statistically significant, while in older referred girls (aged 14-18 years old) it is. Therefore, all the younger individuals who are identified with a surface deformity but without a severe scoliotic curve are at risk for IS development and need to be kept under observation and not discharged from regular follow-up.

It is crucial for everyone who participates to fully recognize the voluntary basis of the program, in order to reduce the financial cost. The financial cost can be either direct or indirect. There is no general consensus among economists as to what constitutes the indirect cost in a cost-effectiveness analysis, because the indirect cost cannot be measured precisely, as it is related to the effectiveness of the school screening program. A more effective screening program has lower indirect cost. Therefore, the economic information on screening for scoliosis which is available to decision-makers should mainly be based on studies of the direct cost of such programs. The direct cost of a screening program can be reduced to a minimum, if it is well organized and performed on a voluntary basis, according to the model of the "Thriasio" school screening program.

\section{Authors' contributions}

TBG created the initial questionnaire, chaired this consensus paper at the Boston SOSORT Meeting, May 13-15, 2007, processed the collected data, collected the literature and contributed in drafting of the manuscript. The following colleagues namely JPO'B*, $\mathrm{MCH}^{*}, \mathrm{TM}^{*}, \mathrm{SN}^{*}, \mathrm{MR}$, ESV* $^{*}, \mathrm{MHW}^{*}, \mathrm{TK}^{*}$ and HRW*, LNS, TN contributed in some way to the improvement of the initial questionnaire. HRW and ESV partially contributed in drafting of the manuscript. *These authors contributed by reviewing, text editing and adding certain text files and references. All authors have read and approved the final manuscript.

\section{Additional material}

\section{Additional file 1}

Consensus paper on school screening questionnaire. The data provided include the complete consensus paper on school screening questionnaire. Click here for file

[http://www.biomedcentral.com/content/supplementary/1748-

7161-2-17-S1.doc]

\section{Additional file 2}

Term definitions pertinent to school screening. The data provided represent definitions for terms related to school screening.

Click here for file

[http://www.biomedcentral.com/content/supplementary/1748-

7161-2-17-S2.doc]

\section{Acknowledgements}

To Dr loannis Kovanis, for his help to feed the responders' answers into Excel file for the proper processing and for contributing to literature processing, Dr. Nikolaos Bardakos for arranging the literature to EndNote program and for his contribution in improving linguistically the text, Mrs. Christina Maziotou for involvement into Greek School screening program, Drs Mark Asher, Robert W. Gaines and Frederico Adler for their very useful and constructive comments on the paper

Also to all the 2007 Boston SOSORT Meeting participants who completed the school screening form and participated in this consensus paper. TB Grivas was the chairman of the consensus paper. 


\section{References}

I. Abbott EV: Screening for scoliosis: a worthwhile preventive measure. Can J Public Health 1977, 68:22-25.

2. Adler NS, Csongradi J, Bleck EE: School screening for scoliosis. One experience in California using clinical examination and moiré photography. West J Med 1984, I 41:631-633.

3. Fowles JV: Adolescent idiopathic scoliosis. $\mathrm{Br}$ Med J I979, I: 1446.

4. Adair IV, Van Wijk MC, Armstrong GW: Moiré topography in scoliosis screening. Clin Orthop Relat Res 1977:165-171.

5. Allen $\mathrm{BL} J \mathrm{~J}$, Ferguson RL: Topics of interest in pediatric orthopedics. Pediatr Clin North Am I985, 32: I333-I345.

6. Amendt LE, Ause-Ellias KL, Eybers JL, Wadsworth CT, Nielsen DH, Weinstein SL: Validity and reliability testing of the Scoliometer. Phys Ther 1990, 70:108-117.

7. School screening programs for the early detection of scoliosis: a position statement Rosemont, IL: American Academy of Orthopaedic Surgeons; 1992.

8. American Academy of Orthopaedic Surgeons Bulletin 1993.

9. Skaggs DL: Referrals from scoliosis screenings. Am Fam Physician 200I, 64(I):32-35.

10. Armstrong GW, Livermore NB 3rd, Suzuki N, Armstrong JG: Nonstandard vertebral rotation in scoliosis screening patients. Its prevalence and relation to the clinical deformity. Spine 1982, 7:50-54.

II. Asher M, Beringer GB, Orrick J, Halverhout N: The current status of scoliosis screening in North America, 1986. Results of a survey by mailed questionnaire. Spine 1989, 14:652-662.

12. Asher M, Beringer GB, Orrick J, Halverhout N: The current status of scoliosis screening in North America 1986: Results of a survey by mailed questionnaire. Scoliosis Screening Symposium, Combined Meeting of the Scoliosis Research Society and the British Scoliosis Society. Hamilton, Bermuda 1986.

13. Asher M, Beringer GB, Orrick J, Halverhout N: What has transpired in North America? Scoliosis Screening Symposium, Combined Meeting of the Scoliosis Research Society and the British Scoliosis Society. Hamilton, Bermuda 1986.

14. Asher MA: Scoliosis evaluation. Orthop Clin North Am 1988, | 9:805-8|4

15. Asher MA: Orthopedic screening: especially congenital dislocation of the hip and spinal deformity. Pediatr Clin North Am 1977, 24:7|3-72|.

16. Asher MA, Adler F, Jacobs RR: Idiopathic adolescent scoliosis. Rationale and techniques of early detection. J Kans Med Soc 1975, 76:285-292.

17. Asher MA, Burton DC: Adolescent idiopathic scoliosis: natural history and long-term treatment effects. Scoliosis 2006, I:2.

18. Ashworth MA: Symposium on school screening for scoliosis. Combined Meeting of the Scoliosis Research Society of North America and the British Scoliosis Society. Bermuda 1986.

19. Ashworth MA, Ersil AK: The measurement of rib hump inclination: a potential aid in scoliosis screening. I5th annual meeting of the Scoliosis Research Society. Chicago, IL 1980.

20. Ashworth MA, Hancock JA, Ashworth L, Tessier KA: Scoliosis screening. An approach to cost/benefit analysis. Spine 1988, I3: I 187-I I88.

21. Aulisa L, Bartolini F, Tamburrelli F, Valassina A: [Early diagnosis of scoliosis: methodologic problem]. Arch Putti Chir Organi Mov 1982, 32:129-137.

22. Baecke JA, Pessers FG, Verbeek AL: [Is screening for scoliosis useful?]. Ned Tijdschr Geneeskd 1984, I 28:2028-2032.

23. Baker EA, Zangger B: School screening for idiopathic scoliosis. Am J Nurs 1970, 70:766-767.

24. Barrett JP, Lee MA: Evaluation of the adolescent for scoliosis after positive school screening. J Miss State Med Assoc I98I, 22:277-279.

25. Beausejour M, Roy-Beaudry M, Goulet L, Labelle H: Patient characteristics at the initial visit to a scoliosis clinic: a cross-sectional study in a community without school screening. Spine 2007, 32: I 349-I 354.

26. Beegel PM, Parisien VM: The early recognition of scoliosis. J Maine Med Assoc 1973, 64:. 56 passim

27. Belstead JS, Edgar MA: Early detection of scoliosis. Br Med J I978, 2:937-938.

28. Benson GM: Spinal curvature in children screening and treatment. SDJ Med 1977, 30:5-9.
29. Benson KD, Benson DR, Wade B: Results of school screening for scoliosis. J Sch Health 1977:483-484.

30. Berntsen E, Risgaard-Petersen B: [Screening of school children for scoliosis. Examination of the back with moire topography and controlled forward bending test]. Ugeskr Laeger 198I, 1 43:3373-3377.

31. Berwick DM: Scoliosis screening: a pause in the chase. Am J Public Health 1985, 75: I 373-1374.

32. Berwick DM: Scoliosis screening. Pediatr Rev 1984, 5:238-246.

33. Biezin AP: [Various remarks on the prevention and treatment of scoliosis]. Ortop Travmatol Protez 1959, 20:38-43.

34. Blachek J: Medical update: scoliosis screening. The Spinal Connection Newsletter 1987, 3:.

35. Bleck EE: School screening for scoliosis. Acta Orthop Scand 1989, 60:123-125.

36. Blount WP: Early recognition and prompt evaluation of spinal deformity. J lowa Med Soc 1969, 59:1015-1024.

37. Blount WP: Early recognition and prompt evaluation of spinal deformity. Wis Med J 1969, 68:245-249.

38. Blount WP: Early recognition and prompt evaluation of spinal deformity. J Sch Health 1970, 40:5I4.

39. Blount WP: Early recognition and prompt evaluation of spinal deformity. J Med Assoc State Ala 1970, 39:749-754.

40. School screening for scoliosis. Br Med J (Clin Res Ed) 1983, 287:963-964.

4I. Broun J, Bennett C, Miller M: Scoliosis detection clinic. Orthopedic Digest 1975:14-16.

42. Bruszewski ], Kamza Z: [Incidence of scoliosis based on an analysis of serial radiography]. Chir Narzadow Ruchu Ortop Pol 1957, 22:115-1 I6.

43. Bunnell WP: An objective criterion for scoliosis screening. J Bone Joint Surg Am 1984, 66: I 381-1387.

44. Bunnell WP: Outcome of spinal screening. Spine 1993, I 8:1572-1580.

45. Bunnell WP: Selective screening for scoliosis. Clin Orthop Relat Res 2005:40-45.

46. Bunnell WP: Screen for scoliosis - with increased credibility. Community Nurse Forum I 1984: I-3.

47. Bunnell WP: Spinal deformity. Pediatr Clin North Am 1986, 33:|475-|487.

48. Bunnell WP: When does scoliosis need referral? Patient Care 1987, 2 I:53-60.

49. Bunnell WP: British Scoliosis Society: school screening update. J Bone Joint Surg Br 1989, 7 I:.

50. Burwell $G$ : The British decision and subsequent events. Spine 1988, I3: I 192-I I94.

51. Burwell G: Current status of screening. 8th Phillip Zorab Scoliosis Symposium; October 26-28, 1988; London 1988.

52. Burwell RG: The use of the scoliometer in the school and clinic. Ist Congress of the European Spinal Deformity Society. Rome, Italy 1986.

53. Burwell RG, Elwood J, James NJ, Webb JK: The use of the scoliometer in the school and clinic. In 3rd Meeting Study Group on Screening and Natural History London: British Scoliosis Society; 1984.

54. Burwell RG, Patterson JF, Webb JK, Wojcik AS: School screening for scoliosis. 5th International Symposium on Surface Topography and Body Deformity. Vienna, Austria 1988.

55. Burwell RG, Stokes IAF, Pekelsky JR, Moreland MS: British Scoliosis Society: Natural History Committee. 4th International Symposium; 1986; Mont Sainte-Marie, Quebec 1986.

56. Burwell RG, Upadhyay SS, Webb JK, Patterson JF, Wojcik AS, Moulton A: Femoral anteversion and the decline angle in I 2-1 3 year old children referred by new screening criteria. A new theory of aetiology. J Pediatr Orthop 1989, 9:349.

57. Burwell RG, Upadhyay SS, Webb JK, Patterson JF, Wojcik AS, Moulton A: Femoral anteversion and the decline angle in I 2-I 3 year old children referred by new screening criteria. A new theory of aetiology. Clin Anat 1989, I:302.

58. Burwell RG, Webb JK, Moore EJ: School screening for scoliosis. Lancet 198I, 2:863.

59. California State Department of Education. Standards for scoliosis screening. Public Scoliosis. Sacramento, CA. I985, 6:6.

60. Cantrell D: Scoliosis: screening potential victims. $R N$ 1976, 39:56. 
6I. Cecilia T: [Fluoroscopic screening for scoliosis]. Orv Hetil 1977, I I 8:27| 9-2720.

62. Cochrane AL, Holland WW: Validation of screening procedures. Br Med Bull 197I, 27:3-8.

63. Moreland M, Pope MS, Armstrong G: Comparison between Moiré and x-ray findings in structural scoliosis. In Moiré fringe topography Edited by: Moreland M, Pope MS, Armstrong G. Oxford: Pergammon Press; 1981.

64. Connolly BH, Michael BT: Early detection of scoliosis. A neurological approach using the asymmetrical tonic neck reflex. Phys Ther 1984, 64:304-307.

65. Cooper B: Scoliosis or schooliosis? The controversy races on. School Nurse Network 1987, 6:

66. Cronis S, Russell AY: Orthopedic screening of children in Delaware public schools. Del Med J 1965, 37:89-92.

67. Cross AW: Health screening in schools. Part II. J Pediatr 1985, 107:653-66I.

68. Dahlberg I, Nachemson AL: The economic aspects of scoliosis treatment Academic Press; 1977.

69. Dangerfield PH, Denron JS, Barnes SB, Drake NB: The assessment of rib-cage and spinal deformity in scoliosis. Surface topography and spinal deformity Proceedings of the 4th International Symposium; September 29-30, 1986; Mont Saint-Marie, Quebec 1986:53-65.

70. Daruwalla JS, Balasubramaniam P: Moiré topography in scoliosis. Its accuracy in detecting the site and size of the curve. J Bone Joint Surg Br 1985, 67:21।-2।3.

71. Debeugny P: [Procedure to follow in the presence of scoliosis in children or adolescents]. Lille Med 1966, I I:1079-1085.

72. Delaware's Public School Orthopaedic Screening Program: State Department of Public Instruction, Division of Public Health. Dover, Delaware.

73. Dendy JM, Chase M, Determann P: School screening for scoliosis - organisation of school and clinic procedure. Physiotherapy 1983, 69:272-276.

74. De Wilde L, Plasschaert F, Cattoir H, Uyttendaele D: Examination of the back using the Bunnell scoliometer in a Belgian school population around puberty. Acta Orthop Belg 1998, 64: | 36- I43.

75. Dickson RA: Screening for scoliosis. Br Med J (Clin Res Ed) I984, 289:269-270.

76. Dickson RA: Scoliosis in the community. Br Med J (Clin Res Ed) 1983, 286: 1745.

77. Dickson RA: Scoliosis in the community. Br Med J (Clin Res Ed) 1983, 286:6|5-6|8.

78. Dickson RA, Archer IA: Scoliosis in the community. Butterworth's International Medical Reviews 1984.

79. Dickson RA, Stamper P, Sharp AM, Harker P: School screening for scoliosis: cohort study of clinical course. $\mathrm{Br}$ Med J 1980, 281:265-267.

80. Dickson RA, Weinstein SL: Bracing (and screening) - yes or no? Jone Joint Surg Br 1999, 81:193-198.

8I. Drennan JC, Campbell JB, Ridge H: Denver: a metropolitan public school scoliosis survey. Pediatrics 1977, 60:193-196.

82. Drummond DS: Recognition and management of scoliosis. Compr Ther 198I, 7:58-65.

83. Drummond DS, Rogala E, Gurr J: School screening, a community project. Quebec Scoliosis Society Meeting. Montreal 1976.

84. Drummond DS, Rogala E, Gurr J: Spinal deformity: natural history and the role of school screening. Orthop Clin North Am 1979, 10:75।-759.

85. Duhaime M, Archambault J, Poitras B: School screening for scoliosis. Quebec Scoliosis Society Meeting. Montreal 1976.

86. Duhaime M, Poitras B, Archambault ]: [Screening for scoliosis in schools. Study on 14,886 x-rays]. Union Med Can 1976, 105:886-887.

87. Dunn BH: Scoliosis detection. ONA J 1975, 2:282-283.

88. Dunn BH, Hakala MW, McGee ME: Scoliosis screening. Pediatrics 1978, 61:794-797.

89. Dvonch VM, Siegler AH, Clopas CC, Bunch WH: The epidemiology of 'schooliosis'. J Pediatr Orthop 1990, 10:206-207.

90. Dwyer AP, Slinger BS, O'Connor JC, Bedbrook GM: School screening for scoliosis: our challenging responsibility. Aust N Z J Surg 1978, 48:439-441.

91. Early screening for spinal defects. IMJ III Med J I977, I 52:420-42I.

92. School screening for scoliosis. Lancet I98I, 2:345-346.
93. Eisner $\mathrm{V}$, Oglesby A: Health assessment of school children. V. Selecting screening tests. J Sch Health 1972, 42:21-24.

94. Eisner $V$, Oglesby $A$ : Health assessment of children. 8. The unexpected health defect. J Sch Health 1972, 42:348-350.

95. Eisner $V$, Oglesby $A$ : Health assessment of school children. I. Physical examinations. J Sch Health 1971, 4 I:239-242.

96. Eisner V, Oglesby A: Health assessment of school children. II. Screening tests. J Sch Health 1971, 41:344-346.

97. Emr J: Functional scolioses of the spine in school-age. Sb Ved Pr Lek Fak Karlovy Univerzity Hradci Kralove 1968, I I:209-225.

98. Fearon T, Vucich J, Butler P, McSweeney WJ, Taylor GA, Markle BM, Hoe J: Scoliosis examinations: organ dose and image quality with rare-earth screen-film systems. AJR Am J Roentgenol 1988, 150:359-362.

99. Ferris B, Edgar M, Leyshon A: Screening for scoliosis. Acta Orthop Scand 1988, 59:417-4I8.

100. Flynn JC, Riddick MF, Keller TL: Screening for scoliosis in Florida schools. J Fla Med Assoc 1977, 64:159-161.

10I. Flynn JC, Riddick MF, Price CT, Keller TL: Present status of scoliosis screening in Florida schools. J Fla Med Assoc 1985, 72:847-85I.

102. Flynn JM: [Bared back for the identification of scoliosis]. Bol Asoc Med P R 1978, 70:45-48.

103. Forrester-Brown M: Scoliosis: importance of early diagnosis. Congr Soc Intl Chir Orthop Traum. Berne 1954.

104. Francis RS: Scoliosis screening of 3,000 college-aged women. The Utah Study - phase 2. Phys Ther 1988, 68:1513-1516.

105. Frontino G, Negri V, Rinaldi E: [Photographic moire method for preliminary diagnosis of spine deformity (author's transl)]. Ateneo Parmense Acta Biomed 1980, 51:33-38.

106. Frost J, Shiratori H, Lam J: Scoliosis screening pilot project-A. Preliminary report to development of a statewide school program. Hawaii Med J 1978, 37:361-362.

107. Gaines RW: Scoliosis and kyphosis, review and current concepts. Mo Med 1980, 77:124-134.

108. Gaines RW, McKinley LM, Leatherman KD: Scoliosis must be diagnosed early. J Ky Med Assoc 1977, 75:23I-234.

109. Gallo M: Campagna profilattica intensiva control gli atteggamenti scoliotici. Ginn Med 1954:91-93.

II0. Godley G: A special report: detecting early signs of scoliosis. Elementary School 1984, 84:357-362.

III. Goldberg C, Blake N, Fogarty E, Dowling F, Regan B: School scoliosis screening: a report. Ir Med J 1987, 80:325-326.

I I2. Goldberg C, Fogarty EE, Blake NS, Dowling F, Regan BF: School scoliosis screening: a review of 21,000 children. Ir Med J 1983, 76:247-249.

113. Goldberg C, Thompson F, Dowling F, Regan BF, Blake NS: Pilot study for a scoliosis screening project in South Dublin. Ir Med J 1980, 73:265-268.

114. Goldberg CJ, Dowling FE, Fogarty EE, Moore DP: School scoliosis screening and the United States Preventive Services Task Force. An examination of long-term results. Spine 1995, 20:1368-1374.

II5. Goldberg CJ, Kaliszer M, Moore DP, Fogarty EE, Dowling FE: Surface topography, Cobb angles, and cosmetic change in scoliosis. Spine 200I, 26:E55-63.

116. Golmiche P: Examen clinique d' un scoliotique. Sem Hop Paris 1956, 32:2901-2903.

117. Golomb M, Taylor TK: Letter: Screening adolescent school children for scoliosis. Med J Aust 1975, 1:761-762.

1 18. Gore DR, PassehI R, Sepic S, Dalton A: Scoliosis screening: results of a community project. Pediatrics 198I, 67:196-200.

119. Greczy I, Sarkany ], Toth J, Nemes ], Bakay A: [Scoliosis screening in Bacs-Kiskun County using the Adams test and the moire technic]. Orv Hetil 1988, 129:883-887.

120. Green PB: Spine deformity screening in Kansas. J Sch Health 1979, 49:56-57.

121. Grivas TB, Arvaniti A, Maziotou C, Manesioti MM, Fergadi A: Comparison of body weight and height between normal and scoliotic children. Stud Health Technol Inform 2002, 91 :47-53.

122. Grivas TB, Dangas S, Polyzois BD, Samelis P: The Double Rib Contour Sign (DRCS) in lateral spinal radiographs: aetiologic implications for scoliosis. Stud Health Technol Inform 2002, 88:38-43.

123. Grivas TB, Dangas S, Samelis P, Maziotou C, Kandris K: Lateral spinal profile in school-screening referrals with and without late 
onset idiopathic scoliosis $10^{\circ}-\mathbf{2 0}$. Stud Health Technol Inform 2002, $91: 25-31$

124. Grivas TB, Maziotou C, Karathanou S, Birli E, Arvaniti A, Vasiliadis E: The cost of the school-screening program in a general hospital. Acta Orthop Hellen 2004, 55:246-250.

125. Grivas TB, Samelis P, Chadziargiropoulos T, Polyzois B: Study of the rib cage deformity in children with 10 degrees-20 degrees of Cobb angle late onset idiopathic scoliosis, using rib-vertebra angles - aetiologic implications. Stud Health Technol Inform 2002, 91:20-24.

126. Grivas TB, Samelis P, Pappa AS, Stavlas P, Polyzois D: Menarche in scoliotic and nonscoliotic Mediterranean girls. Is there any relation between menarche and laterality of scoliotic curves? Stud Health Technol Inform 2002, 88:30-36.

127. Grivas TB, Stavlas P, Koukos K, Samelis P, Polyzois B: Scoliosis and cavus foot. Is there a relationship? Study in referrals, with and without scoliosis, from school screening. Stud Health Technol Inform 2002, 88: I0-14.

128. Grivas TB, Vasiliadis E, Chatziargiropoulos T, Polyzois VD, Gatos K: The effect of a modified Boston brace with anti-rotatory blades on the progression of curves in idiopathic scoliosis: aetiologic implications. Pediatr Rehabil 2003, 6:237-242.

129. Grivas TB, Vasiliadis E, Maziotou C, Beltsios M, Psarakis S, Segos D: Cost analysis of a school-screening program. 4th International Conference on Conservative Management of Spinal Deformities. Boston, USA 2007.

130. Grivas TB, Vasiliadis E, Mouzakis V, Mihas C, Koufopoulos G: Association between adolescent idiopathic scoliosis prevalence and age at menarche in different geographic latitudes. Scoliosis 2006, I:9.

131. Grivas TB, Vasiliadis E, Savvidou O, Dangas S, Triantafyllopoulos G The growth effect in the agreement of scoliosis surface and radiological deformity. Aetiological implications. 14th International Meeting on Advanced Spine Techniques (IMAST). Paradise Island, Bahamas 2007.

132. Grivas TB, Vasiliadis E, Savvidou O, Dangas S, Triantafyllopoulos G: The growth effect in the agreement of scoliosis surface and radiological deformity. Aetiological implications. SRS Eastern European Regional Meeting. InterContinental Hotel, Budapest, Hungary 2007.

133. Grivas TB, Vasiliadis ES, Maziotou C, Savvidou OD: The direct cost of 'Thriasio' school screening program. Scoliosis 2007, 2:7.

134. Grivas TB, Vasiliadis ES, Mihas C, Savvidou O: The effect of growth on the correlation between the spinal and rib cage deformity: implications on idiopathic scoliosis pathogenesis. Scoliosis 2007, 2:11.

135. Grossman TW, Mazur JM, Cummings RJ: An evaluation of the Adams forward bend test and the scoliometer in a scoliosis school screening setting. J Pediatr Orthop 1995, 15:535-538.

136. Gschwend N, Tschui F: [Flat Spine and Lumbar Scoliosis, Their Diagnosis and Prognostic Significance]. Schweiz Med Wochenschr 1963, 93:1387-1393.

137. Zhang GP, Li ZR, Wei XR, Cao YL, Cui QL: Screening for scoliosis among school children in Beijing. Chin Med J (Engl) 1988, 101:151-154.

138. Gunnoe BA: Adolescent idiopathic scoliosis. Orthop Rev 1990 , 19:35-43.

139. Gurr JF: A school screening program that works. Can Nurse $1977,73: 24-29$.

140. Harlin VK, Benson KD, Wade B, Benson DR: Results of school screening for scoliosis in the San Juan Unified School District, Sacramento, California. I Sch Health 1977, 47:483-484.

141. Harrell J, Meehan PL: School screening for spinal deformity. Ona J 1979, 6:203-208.

142. Harrington PR: Scoliosis in the growing spine. Pediatr Clin North Am 1963, 10:225-245.

143. Harris JD, Turner-Smith AR, Fischer, Verlag G: A cost-effectiveness analysis of different types of screening techniques for scoliosis. Surface topogrphy and spinal deformity. 4th International Symposium; September 29-30, 1986; Mont Sainte-Marie, Quebec 1986:243.

144. Harrison CS, Weiler DR: Early recognition of scoliosis. Pa Med 1977, 80:5I-53.

145. Hawes MC: The use of exercises in the treatment of scoliosis: an evidence-based critical review of the literature. Pediatr Rehabil 2003, 6:17I-182.
146. Hawes MC, O'Brien JP: The transformation of spinal curvature into spinal deformity: pathological processes and implications for treatment. Scoliosis 2006, I:3.

147. Heine J, Heine $F$ : [On the incidence of thoracal scoliosis in juveniles (author's transl)]. Z Orthop Ihre Grenzgeb 198I, I 19:340-343.

148. Heipertz W: [Prevention and Treatment of Scoliosis in Infancy and Childhood]. Munch Med Wochenschr 1964, 106:1621-1627.

149. Hensinger R, Cowell HR, MacEwen GD, Cronis S: Orthopaedic screening of school age children: review of a 10 -year experience. Orthop Rev 1975, 4:23-28.

150. Hess WE: Scoliosis - clues to early recognition. Rocky Mt Med J 1967, 64:43-46.

15I. Hill PM, Romm LS: Screening for scoliosis. MCN Am J Matern Child Nurs 1977, 2:156-159.

152. Hipps HE: The diagnosis and treatment of incipient and early idiopathic scoliosis. Am J Orthop 1963, 5:76-82.

153. Horak J: [Scoliosis in school children]. Acta Chir Orthop Traumatol Cech 1952, 19:176-178.

154. Howell JM, Craig PM, Dawe BG: Problems in scoliosis screening. Can J Public Health 1978, 69:293-296.

155. Hungerford DS: Spinal deformity in adolescence. Early detection and nonoperative management. Med Clin North Am 1975, 59:1517-1525.

156. Huurman WW: Scoliosis screening program: eliminating another crippler. California School Health 1977, 13:4.

157. Inoue S: Moiré topography for the early detection and postoperative evaluation of scoliosis. Orthopaedic Research Society 1978.

158. Inoue S: [Screening of scoliosis among school children and the role of orthopedic surgeons]. Nippon Seikeigeka Gakkai Zasshi 1980, 54:701-712.

159. Inoue S, Shinoto A, Ohki I: The moiré topography for early detection of scoliosis and evaluation after surgery. Combined meeting of SRS and Japanese SRS. Kyoto, Japan I977.

160. Jackson RK: School screening with the scoliometer. 3rd Meeting, Study Group on Screening and Natural History British Scoliosis Society London, UK 1984.

16I. Jones SL: Measurement screen for leg length and scoliosis. Phys Ther 1976, 56:188-189.

162. Kane W]: The North American decision in historical perspective. Spine 1988, 13:| |9|.

163. Kane WJ, Brown JC, Hensinger RN, Keller RB: Scoliosis and school screening for spinal deformity. Am Fam Physician 1978, I7:123-127.

164. Karachalios T, Sofianos J, Roidis N, Sapkas G, Korres D, Nikolopoulos $\mathrm{K}$ : Ten-year follow-up evaluation of a school screening program for scoliosis. Is the forward-bending test an accurate diagnostic criterion for the screening of scoliosis? Spine 1999, 24:2318-2324.

165. Kazanskaia LD: [Detection of scoliosis in children of pre-school age by fluorography]. Vestn Rentgenol Radiol 1956, 31:46-50.

166. Kesling KL, Reinker KA: Scoliosis in twins. A meta-analysis of the literature and report of six cases. Spine 1997, 22:2009-20I4. discussion 2015

167. King AG: Scoliosis in the community. Br MedJ (Clin Res Ed) 1983, 286: 1442

168. Koga Y: [The result of the author's screening system of scoliosis in elementary and junior-high schools]. Nippon Seikeigeka Gakkai Zasshi 1986, 60:61-71.

169. Konsbruck R, Cotrel $Y$ : [Results of 10 years' detection of scoliosis organized in the Grand Duchy of Luxembourg]. Bull Soc Sci Med Grand Duche Luxemb 198I, I I 8:6I-7I.

170. Kovacic S: [Spine abnormalities and their prevention]. Lijec Vjesn 1956, 78:459-463

171. Korovessis P, Kyrkos C, Piperos G, Soucacos PN: Effects of thoracolumbosacral orthosis on spinal deformities, trunk asymmetry, and frontal lower rib cage in adolescent idiopathic scoliosis. Spine 2000, 25:2064-207I.

172. Korovessis PG, Stamatakis MV: Prediction of scoliotic cobb angle with the use of the scoliometer. Spine 1996, 21:166I-I666.

173. Koukourakis I, Giaourakis G, Kouvidis G, Kivernitakis E, Blazos J, Koukourakis M: Screening school children for scoliosis on the island of Crete. J Spinal Disord 1997, 10:527-53 I. 
174. Kunz O: Spinal detect in school children. Acta Chir Orthop Traumatol Cech 1962, 29: I I-I7.

175. Laulund T, Sojbjerg JO, Horlyck E: Moire topography in school screening for structural scoliosis. Acta Orthop Scand 1982, 53:765-768.

176. Leaver JM, Alvik A, Warren MD: Prescriptive screening for adolescent idiopathic scoliosis: a review of the evidence. Int J Epidemiol 1982, II:I01-III.

177. Lezberg SF: Screening for scoliosis. Preventive medicine in a public school. Phys Ther 1974, 54:37I-372.

178. Lezberg SF: Early screening for spinal deformity. Clin Mange Phys Ther 1983, 5:115-119.

179. Lonstein JE: Why school screening for scoliosis should be continued. Spine 1988, 13:1 198-1200.

180. Lonstein JE: Natural history and school screening for scoliosis. Orthop Clin North Am 1988, 19:227-237.

18I. Lonstein JE: Screening for spinal deformities in Minnesota schools. Clin Orthop Relat Res 1977:33-42.

182. Lonstein JE: Scoliosis (Letters to the Editor). Lancet 198I, 2:345-346

183. Lonstein JE: Adolescent idiopathic scoliosis: screening and diagnosis. Instr Course Lect 1989, 38:105-1 I3.

184. Lonstein JE, Bjorklund S, Wanninger MH, Nelson RP: Voluntary school screening for scoliosis in Minnesota. J Bone Joint Surg Am I 982, 64:48I-488.

185. Lonstein JE, Winter RB, Moe JH, Bianco AJ, Campbell RG, Norval MA: School screening for the early detection of spine deformities. Progress and pitfalls. Minn Med 1976, 59:5 I-57.

186. Lowe RW: A scoliosis clinic progress report. W V Med J 1975, 7I:I05-107.

187. MacEwen GD, Shands AR Jr: Scoliosis - a deforming childhood problem. Clin Pediatr (Phila) 1967, 6:210-216.

188. Manelli E, Ottolenghi G: [Clinical and radiographical findings on variations in posture of elementary school children in Sanremo]. Minerva Ortop 197I, 22:10-15.

189. Maruyama T, Kitagawa T, Takeshita K, Mochizuki K, Nakamura K: Conservative treatment for adolescent idiopathic scoliosis: can it reduce the incidence of surgical treatment? Pediatr Rehabil 2003, 6:215-219.

190. Murrell GA, Coonrad RW, Moorman CT 3rd, Fitch RD: An assessment of the reliability of the Scoliometer. Spine 1993, 18:709-7|2.

191. Marino V: $L^{\prime}$ indagine schermografica nella diagnosis precoce dela scoliosi. Orizz Ortop Riabilitaz 1958, 3:165-167.

192. Mathews W: Screening and detection of scoliosis. Physician Assist 1984, 8: 10-12.

193. Mau H: Scoliosis screening in West Germany and its pitfalls with Scheuermann's disease. Arch Orthop Trauma Surg 1985, 104:20I-206.

194. Naumovich SS, Molotkov lu N: [Incidence of scoliosis among children of preschool age]. Ortop Travmatol Protez 1973, 34:79-8I.

195. McCarthy RE: Prevention of the complications of scoliosis by early detection. Clin Orthop Relat Res 1987:73-78.

196. Merck \& Co Inc: Spinal Screening Program Handbook Chicago, IL: Scoliosis Research Society and the American Academy of Orthopaedic Surgeons; 1980.

197. Miller D, Lever CS: Scoliosis screening: an approach used in the school. J Sch Health 1982, 52:98-101.

198. Miller MJ: Screening program for scoliosis. Aorn J 1978, 27:1006-1013.

199. Milano C, Rocco P, Paolino G, Greco P, Lotti G: Telethermographic aspects of the dorsolumbar region in idiopathic scoliosis. Ital j Orthop Traumatol 1982, 8:361-367.

200. Mocci A, Bonzi L: La scoliosi negli accertamenti schermografici di massa. Orizz Ortop Tlag 1957, 2:235-242.

20I. Morais T, Bernier M, Turcotte F: Age- and sex-specific prevalence of scoliosis and the value of school screening programs. Am J Public Health 1985, 75:1377-I 380.

202. Morrison AS: Screening in chronic disease New York: Oxford University Press; 1986.

203. Morrissy RT: School screening for scoliosis. Spine 1999 , 24:2584-259l.

204. Morrissy RT: School screening for scoliosis. A statement of the problem. Spine 1988, 13:1195-1197.
205. Moselli M: [Complementary instrumental findings in the diagnosis of functional and structural abnormalities during the developmental stage]. Minerva Ortop 1971, 22:I-9.

206. Montgomery F, Persson U, Benoni G, Willner S, Lindgren B: Screening for scoliosis. A cost-effectiveness analysis. Spine 1990, 15:67-70.

207. Montgomery F, Willner S: Screening for idiopathic scoliosis. Comparison of $\mathbf{9 0}$ cases shows less surgery by early diagnosis. Acta Orthop Scand 1993, 64:456-458.

208. Nachemson A: Prevalence and natural history report. Proceedings of the 17th Meeting of the Scoliosis Research Society; September 22-25, 1982; Denver, CO 1982

209. Nachemson A, Lonstein JE, Weinstein SL: Report of the prevalence and natural history committee New Orleans, Louisiana: The American Academy of Orthopaedic Surgeons; 1982.

210. Nachemson AL, Peterson LE: Effectiveness of treatment with a brace in girls who have adolescent idiopathic scoliosis. A prospective, controlled study based on data from the Brace Study of the Scoliosis Research Society. J Bone Joint Surg Am 1995, 77:815-822.

21 I. Nasca RJ: Newer concepts in the diagnosis and treatment of scoliosis. Ala J Med Sci 1982, 19:284-288.

212. Natural History Committee of the British Scoliosis Society. A multicentre study of back shape in school children. 4th International Symposium of Surface Topography and Spinal Deformity. Mont Sainte-Marie, Quebec, Canada 1986.

213. Negri $V$ : [Incidence of scoliosis in adolescents of the schools of Parma]. Acta Biomed Ateneo Parmense 1982, 53:4I-45.

214. Negrini S, Aulisa L, Ferraro C, Fraschini P, Masiero S, Simonazzi P, Tedeschi C, Venturin A: Italian guidelines on rehabilitation treatment of adolescents with scoliosis or other spinal deformities. Eura Medicophys 2005, 4I: I83-20I.

215. Newman DC, DeWald RL: School screening for scoliosis. IMJ III Med J 1977, I5 I:3 I-34.

216. Newton J: Scoliosis screening update. School Health Alert 1988, 3:1.

217. Nissinen M, Heliovaara M, Tallroth K, Poussa M: Trunk asymmetry and scoliosis. Anthropometric measurements in prepuberal school children. Acta Paediatr Scand 1989, 78:747-753.

218. Nitzschmann L, Reinhardt $\mathrm{H}$ : [Use of screening methods in child and adolescent health protection]. Z Gesamte Hyg 1982, 28:633-635

219. Nottage WM, Waugh TR, McMaster WC: Radiation exposure during scoliosis screening radiography. Spine 198I, 6:456-459.

220. Noonan KJ, Weinstein SL, Jacobson WC, Dolan LA: Use of the Milwaukee brace for progressive idiopathic scoliosis. J Bone Joint Surg Am 1996, 78:557-567.

22I. Nyilasi J, Korkes I, Kiszely G: [The use of thoracic screen photofluofography as mass screening for the incidence of scoliosis]. Orv Hetil 1977, I 18: 1781-1782.

222. O'Brien JP, Van Akkerveeken PF: School screening for scoliosis: results of a pilot study. Practitioner 1977, 21 9:739-742.

223. Ohtsuka Y, Yamagata M, Arai S, Kitahara H, Minami S: School screening for scoliosis by the Chiba University Medical School screening program. Results of 1.24 million students over an 8-year period. Spine 1988, 13:125|-1257.

224. Okamoto Y: [A new method for automatic analysis of scoliotic deformity]. Nippon Seikeigeka Gakkai Zasshi 1987, 61:277-287.

225. Peacock AJ, Morgan MD, Denison DM: Optical screening for scoliosis. Lancet 1981, 2:585.

226. Peacock AJ, Szczekot J, Szwaluk F: [The incidence of scoliosis]. Chir Narzad Ruchu 1957, 22: I I I-I I4.

227. Pennsylvania School Scoliosis Screening Program: Administrative Commonwealth of Pennsylvania Department of Health Harrisburg: Division of School Health; 1984.

228. Pfammatter T: [A series of entire spine examinations in the preparatory school of Naters, Switzerland, in the period of $1977 / 78$ (author's transl)]. Schweiz Rundsch Med Prax 198I, 70:174-183.

229. Pirastu F, Carta G: La schermografia nella diagnosi della scoliosi dell'eta scolare. Rass Med Sarda 1960, 60:537-54I.

230. Pisani G: [Vertebral para-morphism and dysmorphism]. Minerva Ortop 1962, 13:596-598.

23I. Ploumis A, Transfledt EE, Denis F: Degenerative lumbar scoliosis associated with spinal stenosis. Spine J 2007, 7:428-436. 
232. Quick MM, Highriter ME: Is privacy important in scoliosis screening? J Sch Health I98I, 5 I:458-460.

233. Randall FM, Denton TE: Scoliosis screening: a school survey. Ala J Med Sci 1983, 20:395-396.

234. Rapp GF: Spinal screening for scoliosis, kyphosis and lordosis. J Indiana State Med Assoc 1978, 71:33-34.

235. Rauch G, Wahl H: [Early diagnosis of scoliosis and its incidence in the school age]. Z Arztl Fortbild (Jena) 1976, 70:532-535.

236. Reid UV: Screening for adolescent idiopathic scoliosis. Can Nurse 1975, 71:13-I5.

237. Renshaw TS: Screening school children for scoliosis. Clin Orthop Relat Res 1988:26-33.

238. Renshaw TS, Gurnham R, Gage JR: School screening for the early detection of scoliosis in children. Conn Med 1979, 43:|39-|4I.

239. Rigo M, Reiter C, Weiss HR: Effect of conservative management on the prevalence of surgery in patients with adolescent idiopathic scoliosis. Pediatr Rehabil 2003, 6:209-2I4.

240. Risko T: [Diagnosis of scoliosis and the introduction of screening in Hungary]. Orv Hetil 1988, I 29:1562-1563.

24I. Rinsky LA, Gamble JG: Adolescent idiopathic scoliosis. West J Med 1988, |48:|82-19|

242. Robitaille Y, Villavicencio-Pereda C, Gurr J: Adolescent idiopathic scoliosis: epidemiology and treatment outcome in a large cohort of children six years after screening. Int J Epidemiol 1984, 13:319-323.

243. Rogala EJ, Drummond DS, Gurr J: Scoliosis: incidence and natural history. A prospective epidemiological study. J Bone Joint Surg Am 1978, 60:173-176.

244. Rogala EJ, Drummond DS, Gurr JF: Scoliosis incidence and natural history. A prospective epidemiological study of 22,585 school children. I th Annual Meeting of the Scoliosis Research Society Ottawa, Canada 1976.

245. Rowe DE, Bernstein SM, Riddick MF, Adler F, Emans JB, GardnerBonneau D: A meta-analysis of the efficacy of non-operative treatments for idiopathic scoliosis. J Bone Joint Surg Am 1997, 79:664-674.

246. Ruggerone $\mathrm{M}$, Austin JH: Moire topography in scoliosis. Correlations with vertebral lateral curvature as determined by radiography. Phys Ther 1986, 66:1072-1077.

247. Sapkas G, Papagelopoulos PJ, Kateros K, Koundis GL, Boscainos PJ, Koukou Ul, Katonis P: Prediction of Cobb angle in idiopathic adolescent scoliosis. Clin Orthop Relat Res 2003:32-39.

248. Savini R, Cervellati S, Ponzo L, Cioni A, Palmisani M, Rizqallah Y, Gargiulo G, Nardi S, Di Silvestre M: [Occurrence of idiopathic scoliosis in the Bologna district]. Chir Organi Mov 1986, 71: | 19-125.

249. Sells CJ, May EA: Scoliosis screening in public schools. Am J Nurs 1974, 74:60-62.

250. Seward K: Screening students for scoliosis spares them pain and saves you money. American School Board J 1983, I 70:41-43.

25I. Schock CC: 'Making the screen work'. J Ark Med Soc 1984, 80:534-536.

252. School screening for scoliosis. Acta Orthop Scand 1989, 60:123-125.

253. School screening for scoliosis. Lancet 1988, 2:378.

254. Schwab F, Dubey A, Gamez L, El Fegoun AB, Hwang K, Pagala M, Farcy JP: Adult scoliosis: prevalence, SF-36, and nutritional parameters in an elderly volunteer population. Spine 2005 , 30: 1082-1085.

255. Shands AR, Barr JS, Collona PC, Noall L: End-result study of the treatment of idiopathic scoliosis. Report of the Research Committee of the American Orthopaedic Association. J Bone Joint Surg Am 194I, 23:963-977.

256. Shifrin LZ: Recognizing scoliosis early. Am Fam Physician 197I, 4:76-82.

257. Shifrin LZ: Scoliosis-current concepts. Early recognition and aggressive treatment are most important. Clin Pediatr (Phila) 1972, I 1:594-602.

258. Shinoto A: Quantitative analysis of scoliotic deformity by Moire method. Nippon Seikeigeka Gakkai Zasshi 1981, 55: $1703-1718$

259. Shulman HM: School screening in the United Kingdom. Backtalk 1987, 7:9.

260. Shulman HM: School screening in New Jersey. Backtalk 1987 , 1 2:8-9.

26I. Shulman HM: School screening - where do we go from here? Backtalk 1986, I I:2, I3.
262. Smyrnis PN, Valavanis J, Alexopoulos A, Siderakis G, Giannestras NJ: School screening for scoliosis in Athens. J Bone Joint Surg $\mathrm{Br}$ 1979, 6I-B:215-217.

263. Smyrnis PN, Valavanis J, Voutsinas S, Alexopoulos A, lerodiaconou M Incidence of scoliosis in the Greek islands. In 6th Symposium on Scoliosis; Cardiothoracic Institute, Brompton Hospital, London Edited by: Zorab PA, Siegler D. Academic Press; 1979:13-18.

264. Smyrnis T, Antoniou D, Valavanis J, Zachariou C: Idiopathic scoliosis: characteristics and epidemiology. Orthopedics 1987, 10:921-926

265. Sojbjerg JO, Laulund T, Horlyck E: [Screening for scoliosis with Moiré topography]. Ugeskr Laeger 1982, I 44:3576-3579.

266. Steno M: A survey of scoliosis incidence in Slovakia. Acta Chir Orthop Traumatol Cech 1979, 46:18-2I.

267. Stirling AJ, Smith RM, Dickson RA: Screening for scoliosis: the problem of arm length. $\mathrm{Br}$ Med J (Clin Res Ed) 1986, 292:1305-1306.

268. Stokes IA, Moreland MS: Moiré measurements. Phys Ther 1987, 67:278-280

269. Study Group on Screening and Natural History of the British Scoliosis Society. Abridged first report on the multicentre study and plans for the future. British Scoliosis Society Annual Meeting. Cambridge, UK 1986.

270. Soucacos PN, Soucacos PK, Zacharis KC, Beris AE, Xenakis TA: School-screening for scoliosis. A prospective epidemiological study in northwestern and central Greece. J Bone Joint Surg Am 1997, 79: | 498-I503.

27I. Soucacos PN, Zacharis K, Gelalis J, Soultanis K, Kalos N, Beris A, Xenakis T, Johnson EO: Assessment of curve progression in idiopathic scoliosis. Eur Spine J 1998, 7:270-277.

272. Sullivan JA, Tompkins SF: Development of a scoliosis screening program in Oklahoma schools. J Okla State Med Assoc 1978, 71:52-56.

273. Takemitsu T: Incidence of scoliosis in Japan by mass screening examination of school children. Combined Meeting of the Scoliosis Research Society and the Japanese Scoliosis Research Society. Kyoto, Japan 1977.

274. Takemitsu Y: Scoliosis - screening methods and the subsequent management. Nippon Seikeigeka Gakkai Zasshi 198I, 55:243-257.

275. Takemitsu Y, Harada Y, Ando M: Incidence of scoliosis in Japan by mass screening examination of school children. Orthop Trans 1978, 2:278.

276. Taylor C: Six years of school screening by physical education teachers. Combined British Scoliosis Society and Nordic Scoliosis Society Conference. Freeman Hospital, New Castle I99I.

277. Taylor JR: Scoliosis screening in the Kimberleys. Med J Aust 1983, I:352.

278. Taylor JR, Slinger BS: Scoliosis screening and growth in Western Australian students. Med J Aust 1980, I:475-478.

279. Taylor TK, Bushell G, Ghosh P: School screening for scoliosis: a look inside Pandora's box. Aust N Z J Surg 1978, 48:44I-443.

280. Taylor TK, Bushell G, Ghosh P: School screening for scoliosis: a Pandora's box. Aust N ZJ Surg 1978, 48:2-3.

28I. Tenney HK: 1974 report on scoliosis screening. A supplement to slow dangerous curve. Wisconsin Department of Public Instruction 1974.

282. Thompson F, Walsh M, Colville J: Moire topography: a method of screening for adolescent idiopathic scoliosis. Ir Med J 1985, 78:162-165.

283. Tolo VT: Treatment, follow-up, or discharge. Spine 1988, 13:1189-1190.

284. Tones M, Moss N, Polly DW Jr: A review of quality of life and psychosocial issues in scoliosis. Spine 2006, 31:3027-3038.

285. Torell G, Nordwall A, Nachemson A: The changing pattern of scoliosis treatment due to effective screening. J Bone Joint Surg Am 198I, 63:337-34I.

286. Turcotte F, Rochon TM, Roy L, Gallien R: Scoliosis screening revisited. Scoliosis Research Society. Montreal I98I.

287. Upadhyay SS, Burwell RG, Nicholson UJL, Webb JK: The integrated imaging system [ISIS] and the scoliometer for recording back shape in scoliosis. A reliability and comparative study revealing positional changes in back contour (hump dynamics). 4th International Symposium on Surface Topography and Spinal Deformity. Mont Sainte-Marie, Quebec, Canada 1986.

288. Upadhyay SS, Burwell RG, Nicholson UJL, Webb JK: The integrated shape imaging system (ISIS) and the scoliometer for record- 
ing back shape in scoliosis. A reliability study. Proceedings of the British Scoliosis Society; March 2I-22, 1986; Cambridge, UK 1986.

289. Upadhyay SS, Burwell RG, Webb JK: Hump changes on forward flexion of the lumbar spine in patients with idiopathic scoliosis. A study using ISIS and the Scoliometer in two standard positions. Spine 1988, 13:|46-15I.

290. Upadhyay SS, Burwell RG, Webb JK: ISIS and scoliometer for recording angle of trunk inclination in idiopathic scoliosis: an error study and a comparison revealing differences in the lumbal region. Proceedings of the Ist Congress of the European Spinal Deformities Society; April 16-19, 1986; Rome, Italy 1986.

291. Screening for adolescent idiopathic scoliosis. Policy statement. US Preventive Services Task Force. JAMA 1993, 269:2664-2666.

292. US Preventive Service Task Force. Screening for idiopathic scoliosis in adolescents. Recommendation statement. Agency for Healthcare Research and Quality, 540 Gaither Road, Rockville, MD 20850; 2004. uspstf@ahrq.gov

293. Screening for idiopathic scoliosis in adolescents: a brief evidence update for the U.S. Preventive Services Task Force.

[http://www.preventiveservices.ahrq.gov]. Guide to Clinical Preventive Services, 3rd Edition: Periodic Updates. AHRQ Publications Clearinghouse (call I-800-358-9295, ahrqpubs@ahrq.gov. Web site of the National Guideline Clearinghouse ${ }^{\mathrm{TM}}$ [http://www.guideline.gov]. AHRQ Pub. No. 050568-B. 2004.

294. Valavanis J, Bountis A, Zachariou C, Kokkonis D, Anagnostou D, Giahos D, Daskalakis E: Three-dimensional brace treatment for idiopathic scoliosis. In Three-dimensional analysis of spinal deformities D'Amico: IOS Press; 1995:337-340.

295. Valentino B, Maccauro L, Mango G, Melito F, Fabozzo A: Electromyography for the investigation and early diagnosis of scoliosis. Anat Clin 1985, 7:55-59.

296. Verrier M, Shillington ER, Wright TA, Crawford JS, Williams J]: Testing reliability and validity of screening methods for scoliosis Toronto: Health Care Research Unit Publication; 1979.

297. Verrier M, Shillington ER, Wright TA, Crawford JS, Williams JJ: Comparing methods of screening for scoliosis: testing for reliability and Validity. A research report Toronto: Health Care Research Unit, University of Toronto; 1979.

298. Vinchon B: Presentation of an apparatus for measurement of scoliotic gibbosities. Rev Chir Orthop Reparatrice Appar Mot 1965, $5 \mathrm{I}: 643-644$.

299. Viviani GR: Assessment and treatment of mild adolescent scoliosis. Mod Med Canada 1981, 36:819-823.

300. Viviani GR, Budgell L, Dok C, Tugwell P: Assessment of accuracy of the scoliosis school screening examination. Am J Public Health 1984, 74:497-498.

30I. Waisbrod V, Waisbrod H: Scoliosis in a school population. Harefuah 1979, 97:63-64.

302. Wallace AP: A scoliosis screening program. J Sch Health 1977 , 47:619-620.

303. Warner KE, Luce BR: Cost-benefit and cost-effectiveness analysis in health care Ann Arbor, MI: Hearth Administration Press; 1982.

304. Warren M, Leaver J, Alvik A: School screening for scoliosis. Lancet 1981, 2:522.

305. Webster KP: Planning and implementing health screening programs. J Sch Health 1980, 50:493-495.

306. Weidenbaum M, Riseborough $E$ : The effect of school screening on the diagnosis and treatment of scoliosis. Annual Meeting of the Scoliosis Research Society. Toronto, Canada 1981.

307. Weierman RJ, Lowell HA, Nadel CI, Pojedinec J]: Scoliosis. To refer or not to refer. Prim Care 1980, 7:287-295.

308. Weiler DR: Letter: Screening for scoliosis. Phys Ther 1974, 54:775-776.

309. Weiler DR: Scoliosis screening. J Sch Health 1974, 44:563-565.

310. Weiss HR: Idiopathic scoliosis: how much of a genetic disorder? Report of five pairs of monozygotic twins. Dev Neurorehabil 2007, 10:67-73.

311. Weiss HR, Negrini S, Hawes MC, Rigo M, Kotwicki T, Grivas TB, Maruyama T: Physical exercises in the treatment of idiopathic scoliosis at risk of brace treatment - SOSORT consensus paper 2005. Scoliosis 2006, I:6.

312. Weiss HR, Negrini S, Rigo M, Kotwicki T, Hawes MC, Grivas TB, Maruyama $T$, Landauer F: Indications for conservative management of scoliosis (guidelines). Scoliosis 2006, I:5.
313. Weiss HR, Weiss G, Petermann F: Incidence of curvature progression in idiopathic scoliosis patients treated with scoliosis in-patient rehabilitation (SIR): an age- and sex-matched controlled study. Pediatr Rehabil 2003, 6:23-30.

314. Weiss HR, Weiss G, Schaar HJ: Incidence of surgery in conservatively treated patients with scoliosis. Pediatr Rehabil 2003, 6: III-II8.

315. Williams Jl: Criteria for screening: are the effects predictable? Spine 1988, I3: I 178-I I86.

316. Williams Jl, Herbert MA: Is school screening reliable? Orthopaedic Transactions 1985, 9:110-1II.

317. Willner S: A comparative study of the efficiency of different types of school screening for scoliosis. Acta Orthop Scand 1982, 53:769-774.

318. Willner S: Spinal pantograph - a non-invasive technique for describing kyphosis and lordosis in the thoraco-lumbar spine. Acta Orthop Scand 198I, 52:525-529.

319. Willner S: Moire topography - a method for school screening of scoliosis. Arch Orthop Trauma Surg 1979, 95:181-185.

320. Willner S: Moire topography-a non-invasive method for diagnosis and documentation of scoliosis in screening of children. Lakartidningen 1982, 79:2233-2236.

32I. Willner S: School screening in Malmo. Scoliosis prevention Praeger Publishers; 1985

322. Winter RB: Scoliosis and other spinal deformities. Acta Orthop Scand 1975, 46:400-424.

323. Winter RB, Lonstein JE: To brace or not to brace: the true value of school screening. Spine 1997, 22:1283-1284.

324. Winter RB, Moe JH: A plea for the routine school examination of children for spinal deformity. Minn Med 1974, 57:419-423.

325. Wynne Ej: Scoliosis: to screen or not to screen. Can J Public Health 1984, 75:277-280.

326. Yawn BP, Yawn RA, Hodge D, Kurland M, Shaughnessy WJ, Ilstrup D, Jacobsen SJ: A population-based study of school scoliosis screening. JAMA 1999, 282: | 427-| 432.

327. Zhang GB, Li ZR, Wei XR: Moiré topography in school screening for scoliosis. Zhonghua Wai Ke Za Zhi 1987, 25:387-389.

328. Ziporyn $T$ : Scoliosis management now subject of numerous questions. JAMA I985, 254:3009-30II. 3015-3006, 3019

329. The periodic health examination. Canadian Task Force on the Periodic Health Examination. Can Med Assoc J 1979, I 21: | | $93-1254$

330. U.S. Preventive Services Task Force issues scoliosis screening policy. Am Fam Physician 1993, 47:1876-1877.

33I. Cote P, Kreitz BG, Cassidy JD, Dzus AK, Martel J: A study of the diagnostic accuracy and reliability of the Scoliometer and Adam's forward bend test. Spine 1998, 23:796-802. discussion 803

332. O'Brien JP: Personal communication. 2007.

333. University of lova Hospitals and Clinics. School screening programs [http://www.uihealthcare.com/depts/medmuseum/ wallexhibits/scoliosis/present/detection.html]

334. Maruyama T: Personal communication. 2007.

335. The National Self-Detection Program for Scoliosis [http://www.scoliosis-australia.org/pdfs/ self detection program download06.pdf

336. Scoliosis screening in Arkansas USA guidelines [http://www.healthyarkansas.com/rules regs/Scoliosis Screening.pdf]

337. Feipel V, Aubin CE, Ciolofan OC, Beausejour M, Labelle H, Mathieu PA: Electromyogram and kinematic analysis of lateral bending in idiopathic scoliosis patients. Med Biol Eng Comput 2002, 40:497-505.

338. Jaremko JL, Poncet P, Ronsky J, Harder J, Dansereau J, Labelle H, Zernicke RF: Estimation of spinal deformity in scoliosis from torso surface cross sections. Spine 2001, 26:1583-159|.

339. Jaremko JL, Poncet P, Ronsky J, Harder J, Dansereau J, Labelle H, Zernicke RF: Comparison of Cobb angles measured manually, calculated from 3-D spinal reconstruction, and estimated from torso asymmetry. Comput Methods Biomech Biomed Engin 2002, 5:277-28I.

340. Leroux MA, Zabjek K, Simard G, Badeaux J, Coillard C, Rivard CH: A noninvasive anthropometric technique for measuring kyphosis and lordosis: an application for idiopathic scoliosis. Spine 2000, 25:1689-1694. 
34I. Leroux MA, Zabjek K, Simard G, Coillard C, Rivard CH: Estimated kyphosis and lordosis changes at follow-up in patients with idiopathic scoliosis. J Pediatr Orthop 2002, 22:73-79.

342. Liu XC, Thometz JG, Lyon RM, Klein J: Functional classification of patients with idiopathic scoliosis assessed by the Quantec system: a discriminant functional analysis to determine patient curve magnitude. Spine 200I, 26:1274-1278. discussion 1279

343. Poncet $\mathrm{P}$, Dansereau J, Labelle $\mathrm{H}$ : Geometric torsion in idiopathic scoliosis: three-dimensional analysis and proposal for a new classification. Spine 200I, 26:2235-2243.

344. Raso VJ, Lou E, Hill DL, Mahood JK, Moreau MJ, Durdle NG: Trunk distortion in adolescent idiopathic scoliosis. J Pediatr Orthop 1998, I 8:222-226.

345. Klisic P, Nikolic Z: Attitudes scoliotiques et scolioses idiopathiques: prévention à l'école. Personal communication. Journées Internationales sur la prévention des scolioses à l'âge scolaire Rome 1982.

346. Mollon G, Rodot JC: Scolioses structurales mineures et kinesithérapie. Etude statistique comparative et résultats. Kinésithér Scient 1986, 244:47-56.

347. Stone B, Beekman C, Hall V, Guess V, Brooks HL: The effect of an exercise program on change in curve in adolescents with minimal idiopathic scoliosis. A preliminary study. Physical Therapy 1979, 59:759-763.

348. Rigo M, Quera-Salvá G, Puigdevall N: Effect of the exclusive employment of physiotherapy in patients with idiopathic scoliosis. Retrospective study. Proceedings of the I I th International Congress of the World Confederation For Physical Therapy London. 28 July -2 August 1991:1319-1321.

349. Ferraro C, Masiero S, Venturin A: Effect of exercise therapy on mild idiopathic scoliosis. Preliminary result. Europa Medico Physica 1998, 34:25-3I.

350. Den Boer WA, Anderson PG, Limbeek : Treatment of idiopathic scoliosis with with side-shift therapy: an initial comparison with a brace treatment historical cohort. Eur Spine J 1999, 8:406-4I0.

35I. Negrini S, Antonini G, Carabalona R, Minozzi S: Physical exercises as a treatment for adolescent idiopathic scoliosis. A systematic review. Ped Rehab 2003, 6:227-235.

352. Lenssinck ML, Frijlink AC, Berger MY, Bierman-Zeinstra SM, Verkerk $K$, Verhagen AP: Effect of bracing and other conservative interventions in the treatment of idiopathic scoliosis in adolescents: A systematic review of clinical trials. Phys Ther 2005, 85( I 2): I 329-39.

353. Dickson RA, Leatherman KD: Cotrel traction, exercises, casting in the treatment of idiopathic scoliosis. A pilot study and prospective randomized controlled clinical trial. Acta Orthop Scand 1978, 49(1):46-8.

354. Otman S, Kose N, Yakut Y: The efficacy of Schroth s 3-dimensional exercise therapy in the treatment of adolescent idiopathic scoliosis in Turkey. Saudi Med J 2005, 26(9): | 429-35.

355. Maryama T, Kitagawal T, Takeshita K, Nakainura K: Side shift exercise for idiopathic scoliosis after skeletal maturity. Stud Health Technol Inform 2002, 91:36I-4.

356. Weiss HR: The Schroth scoliosis-specific back school - initial results of a prospective follow-up study. Z Orthop Ihre Grenzgeb 1995, I33(2): I |4-7.

357. Danielsson AJ, Hasserius R, Ohlin A, Nachemson AL: A prospective study of brace treatment versus observation alone in adolescent idiopathic scoliosis: a follow-up mean of 16 years after maturity. Spine 2007, 32(20):2198-207.

358. Natiopnal Scoliosis Foundation [http://www.scoliosis.org/ resources/medicalupdates/screeningoutcome.php]

359. Grivas TB, Vasiliadis E, O'Brien JP: How to improve the effectiveness of school screening for idiopathic scoliosis. In Ist SOSORT Instructional Course Lecture Book Edited by: Grivas TB. Amsterdam: IOS Press; 2008 in press.

360. Gehlbach SH: Interpreting the medical literature New York: McGrawHill Inc; 1993.

36I. Gaeta T: Screening and diagnostic tests. 2005 [http://emedicine.com/emerg/topic770.htm].

362. Scoliosis Research Sosciety [http://www.srs.org/members/statements/school screening.asp]

363. Sox HC Jr, Woolf SH: Evidence-based practice guidelines from the US Preventive Services Task Force. JAMA I993, 269:2678.
364. Brief Evidence Update. Screening for Idiopathic Scoliosis in dolescents. U.S. Preventive Services Task Force (USPSTF) [http://www.ahrq.gov/clinic/3rduspstf/scoliosis/scolioup.htm]
Publish with Biomed Central and every scientist can read your work free of charge

"BioMed Central will be the most significant development for disseminating the results of biomedical research in our lifetime. "

Sir Paul Nurse, Cancer Research UK

Your research papers will be:

- available free of charge to the entire biomedical community

- peer reviewed and published immediately upon acceptance

- cited in PubMed and archived on PubMed Central

- yours - you keep the copyright 